\title{
A LONGITUDINAL STUDY OF THE OUTCOMES FROM PARTICIPATION IN WILDERNESS ADVENTURE EDUCATION PROGRAMS
}

\author{
A Thesis \\ Presented to \\ the Faculty of California Polytechnic State University, \\ San Luis Obispo
}

\author{
In Partial Fulfillment \\ of the Requirements for the Degree \\ Master of Science in Agriculture
}

By

Jason Phillip Cummings

December 2009 
(C) 2009

Jason Phillip Cummings ALL RIGHTS RESERVED 


\section{COMMITTEE MEMBERSHIP}

TITLE:

AUTHOR:

DATE SUBMITTED:

COMMITTEE CHAIR:

COMMITTEE MEMBER:

COMMITTEE MEMBER:
A Longitudinal Study of the Outcomes from Participation in Wilderness Adventure Education Programs

Jason Phillip Cummings

December 2009

Marni Goldenberg, Associate Professor, Recreation, Parks, and Tourism Administration Department

Jerusha Greenwood, Assistant Professor, Recreation, Parks, and Tourism Administration Department

Daren Connor, Assistant Director of Programs, Associated Students, Inc. 


\begin{abstract}
A Longitudinal Study of the Outcomes from Participation in Wilderness Adventure Education Programs

Jason Phillip Cummings
\end{abstract}

The results from this study suggest that participants of wilderness adventure education programs offered by Outward Bound and the National Outdoor Leadership School felt challenged by many of the experiences from their programs. Interactions with their group helped in dealing with the challenges presented by the experience. The development of hard skills gave participants a confidence in their abilities to survive and feel safe in these wilderness environments, which allowed them to relax and enjoy the experience, develop new perspectives, become motivated and inspired, and develop a sense of independence. Participants developed a sense of growth and maturity from their experiences, which upon reflection led to a sense of accomplishment. This sense of accomplishment led to transference of program benefits and values into participants' lives, particularly in greater self-respect/esteem/confidence.

The purpose of this study was to gain a better understanding of the outcomes that individuals experienced from wilderness adventure programs and the effects they had on participants' lives. Means-end theory was used to understand the outcomes, more specifically attributes, consequences, and values, and their connections to each other. This study was longitudinal in nature and a comparison between the original data collection and follow-up interviews was done to investigate reported change in values over time. The results from this study show that the outcomes from participation in the Outward Bound and NOLS programs were transferring into participant's lives and leaving a lasting impression.

Keywords: wilderness adventure education, Outward Bound, National Outdoor Leadership School, outcomes, longitudinal study, means-end theory, transference 


\section{ACKNOWLEDGEMENTS}

I would like to acknowledge the contributions of the following individuals who helped me complete this thesis:

Dr. Marni Goldenberg, my dedicated and supportive advisor who was with me every step of the way. Sometimes I needed a little push, sometimes a word of encouragement, and many times validation for the long hours spent on this work. Dr. Goldenberg provided this guidance and I am deeply grateful to her. Dr. Jerusha Greenwood, a supportive and encouraging committee member who helped immensely with grammatical and contextual revisions to the thesis. Daren Connor, also a supportive and encouraging committee member. Dr. Bill Hendricks, for asking the tough but necessary questions concerning my research. Jeff Reimer, instructional support technician for the college of Agriculture, whose technical expertise helped with the follow-up phone interviews and for providing a space in which to work on campus. Katherine Wassenberg, a fellow graduate student in Recreation, Parks, and Tourism, for her work on this longitudinal study and for her understanding and compassionate ear that listened to my complaints and frustrations.

My fellow graduate students from the Natural Resources Management Department who shared not only the physical space of the grad room with me but also their friendship and support. Since they were also working on completing a thesis, they could sympathize with the trials and tribulations with completing it.

To the OB and NOLS participants, who volunteered to participate in interviews, without which this thesis would not have been possible.

I would also like to express my gratitude for the financial support received from the USDA McIntyre-Stennis Grant, the Agriculture Research Initiative Grant, and from Cal Poly 
State University, specifically the Hull Graduate Assistantship and the Graduate Equity

Fellowship.

Finally, to my parents who have given such support, encouragement, and love along the way that I don't think I would have finished without it. 


\section{TABLE OF CONTENTS}

Page

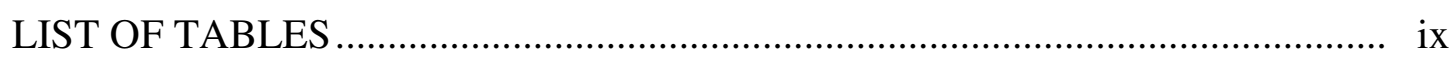

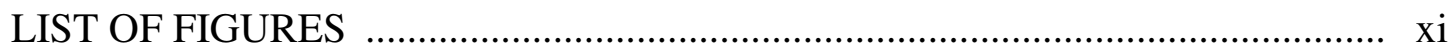

CHAPTER

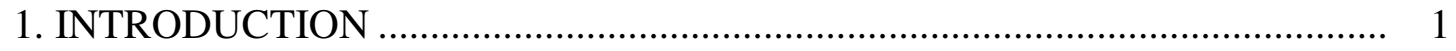

Background Information ........................................................... 1

Need for the Study ........................................................................... 3

Contribution of the Study........................................................... 4

Purpose of the Study ..................................................................... 5

Objectives ............................................................................ 5

Research Questions ............................................................. 5

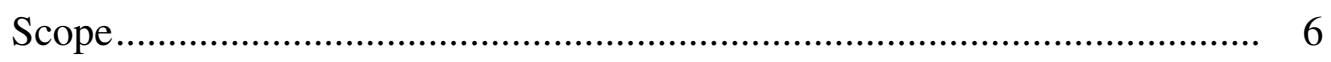

Theoretical Framework ............................................................... 7

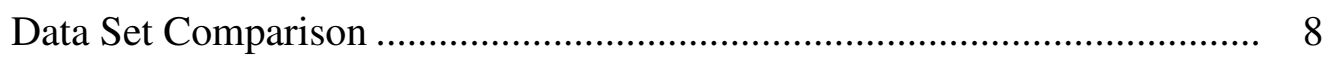

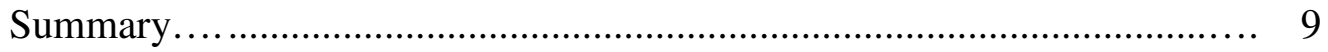

Definition of Terms........................................................................ 10

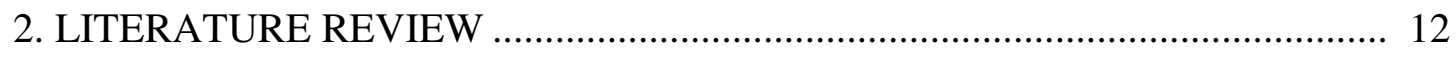

Experiential Education ............................................................. 12

Wilderness Adventure Education Theory ............................................ 20

Factors Which Influence the Effects of Outdoor Education Programs......... 27

Benefits from Participation in Wilderness Adventure Programs................. 29

Current State of Research .............................................................. 30 
Theoretical Framework ................................................................ 33

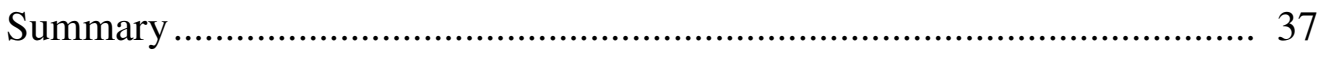

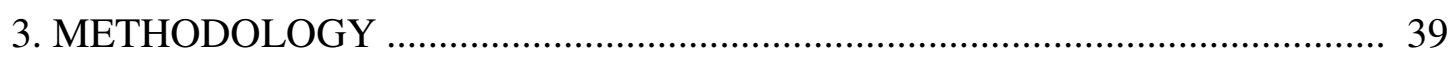

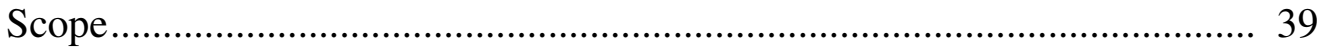

Description of Subjects .................................................................. 39

Instrument Used in Data Collection..................................................... 41

Description of Procedures ................................................................. 43

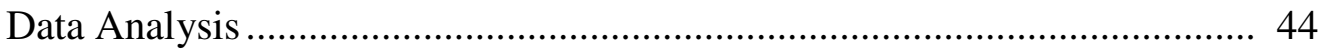

Validation Criteria ......................................................................... 46

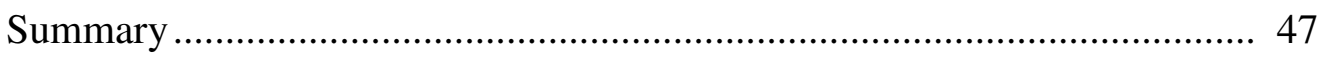

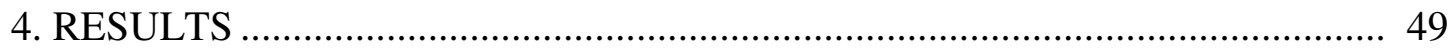

Descriptive Findings .................................................................. 49

Means-End Analysis ................................................................ 59

Comparison of Data Sets ............................................................ 70

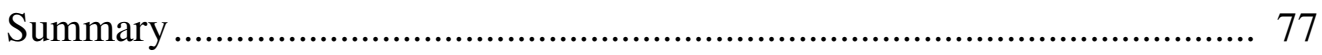

5. DISCUSSION AND INTERPRETATION .............................................. 79

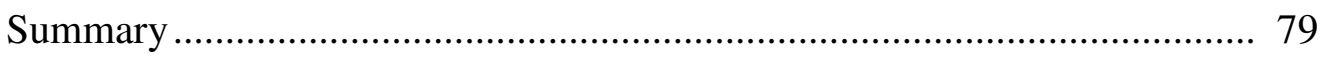

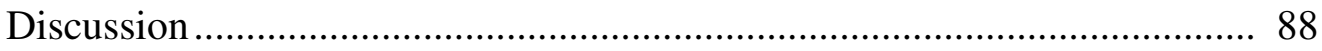

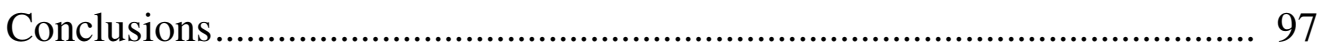

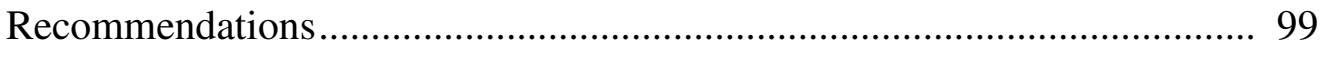

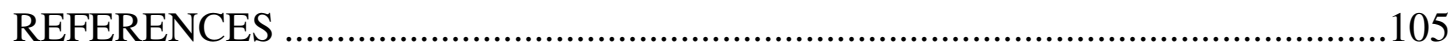

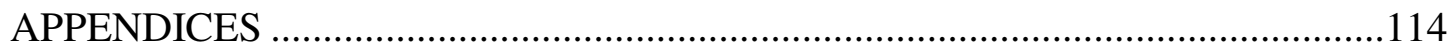

Appendix A: Initial Data Collection Interview Script ...............................114 
Appendix B: Two Year Follow-Up Phone Interview Script .........................116

Appendix C: Combined Outcomes List - OB/NOLS Data .............................118 


\section{LIST OF TABLES}

Page

Table 4.1. Participation in Initial Data Collection by Organization

Table 4.2. Participation in Initial Data Collection by Gender.....

Table 4.3. Participation in Two Year Follow-Up Data Collection by

Organization

Table 4.4. Participation in Two Year Follow-Up Data Collection by Gender......50

Table 4.5. Participation in Initial Data Collection by Ethnic/Racial Group .........51

Table 4.6. Participation in Two Year Follow-Up Data Collection by

Ethnic/Racial Group .51

Table 4.7. Participation in Initial Data Collection by Age Group .52

Table 4.8. Participation in Two Year Follow-Up Data Collection by Age Group .53

Table 4.9. Participation in Initial Data Collection by Occupation

Table 4.10. Participation in Two Year Follow-Up Data Collection by Occupation

Table 4.11. Previous Attendance for Participants of Initial Data Collection .54

Table 4.12. Previous Attendance for Participants of Two Year Follow-Up Data Collection

Table 4.13. Course Length for Participants of Initial Data Collection .55

Table 4.14. Course Length for Participants of Two Year Follow-Up Data Collection

Table 4.15. Likelihood of Participants Recommending an OB/NOLS Course to a Friend from Initial Data Collection. .56

Table 4.16. Likelihood of Participant Recommending an OB/NOLS Course to a Friend from Two Year Follow-Up Data Collection .57

Table 4.17. OB Participants from Initial Data Collection by Gender. .57 
Table 4.18. OB Participants from Two Year Follow-Up Data Collection by Gender. .58

Table 4.19. NOLS Participants from Initial Data Collection by Gender .58

Table 4.20. NOLS Participants from Two Year Follow-Up Data Collection by Gender

Table 4.21. Chi-Square Test of Independence for the Value Fun and Enjoyment of Life.....

Table 4.22. Chi-Square Test of Independence for the Value Self-Awareness .......71

Table 4.23. Chi-Square Test of Independence for the Value Self-Fulfillment .......72

Table 4.24. Chi-Square Test of Independence for the Value Self-Respect/ Esteem/Confidence .72

Table 4.25. Chi-Square Test of Independence for the Value Sense of Accomplishment....

Table 4.26. Chi-Square Test of Independence for the Value Sense of Belonging .73

Table 4.27. Chi-Square Test of Independence for the Value Transference. .73

Table 4.28. Chi-Square Test of Independence for the Value Warm Relationships with Others..... .73

Table 4.29. Goodness-of-Fit Test for the Value Fun and Enjoyment of Life .........74

Table 4.30. Goodness-of-Fit Test for the Value Self-Awareness ..........................75

Table 4.31. Goodness-of-Fit Test for the Value Self-Fulfillment .........................75

Table 4.32. Goodness-of-Fit Test for the Value Self-Respect/Esteem/ Confidence .75

Table 4.33. Goodness-of-Fit Test for the Value Sense of Accomplishment ...........76

Table 4.34. Goodness-of-Fit Test for the Value Sense of Belonging ....................76

Table 4.35. Goodness-of-Fit Test for the Value Transference ...............................76

Table 4.36. Goodness-of-Fit Test for the Value Warm Relationships with Others 


\section{LIST OF FIGURES}

Page

Figure 2.1. Outward Bound Process Model ...................................................26

Figure 2.2. McKenzie Processing Model ......................................................22

Figure 4.1. Hierarchical Value Map for All Participants .................................63

Figure 4.2. Hierarchical Value Map for Outward Bound Participants .................66

Figure 4.3. Hierarchical Value Map for NOLS Participants ............................69 


\section{CHAPTER 1}

\section{INTRODUCTION}

This study was undertaken to further understand the outcomes individuals obtain from participation in wilderness adventure education programs. This chapter will review the background information on the subject of interest; review the need for the study and its contribution to the larger scientific community; state the purpose, including the objectives and research questions; briefly explain the scope; highlight the theoretical framework; explain the data set comparison; and list definitions for terms specific to the study.

\section{Background Information}

Experiential education is a philosophy and methodology in which educators engage learners in directed experience and focused reflection in order to enhance knowledge (Martin, Cashel, Wagstaff, \& Breunig, 2006). Martin et al. noted that out of experiential education philosophy grew the concept of outdoor education, where learning was concentrated around the relationships between people and natural resources. Martin et al. concluded that the primary disciplines of outdoor education were adventure education and environmental education. Priest (1999a) found that adventure education is concerned with personal and interpersonal relationships among people and providing opportunities for growth through adventure experiences that take place in natural environments.

Adventure experiences have become the widely accepted name for activities that employs risk and challenge in an outdoor setting (Webb, 1999). Adventure experiences can include recreational pursuits in the outdoors, such as rock climbing, backpacking, and kayaking or artificial adventure environments, such as a high ropes course. Raiola and O'Keefe (1999) found 
that the common thread that all wilderness adventure experiences share is exposure to elements of uncertainty, real or perceived risk, excitement, interaction with nature, and effort.

One of the pioneering organizations in wilderness adventure education is Outward Bound. Outward Bound's original purpose was to teach merchant seaman and other young men skills that would help them survive at sea during World War II, as well as benefit other aspects of their lives (Miner, 1999). Miner concluded that Outward Bound played a pivotal role in the outdoor education movement and helped set standards for adventure programming in terms of safety, program design, and leadership. Since the early days Outward Bound has enjoyed substantial success and growth, becoming the largest and most widespread adventure education institution in the U.S. and abroad (Outward Bound Wilderness, 2009).

A testament to Outward Bound's success is the array of spin-off and adaptive programs that took root and deeply influenced the experiential education movement (Hirsch, 1999). One of the most successful spin-off organizations from Outward Bound is the National Outdoor Leadership School (NOLS), founded in 1965 by mountaineer Paul Petzoldt. Petzoldt had been chief instructor for the Colorado Outward Bound School when he realized the need for better prepared leaders capable of leading others in the wilderness (Bachert, 1999). The current mission of NOLS is "to be the leading source of wilderness skills and leadership that serve people and the environment" (NOLS Mission, 2009, II 1). Bachert concluded that NOLS is widely recognized as an international leader in the field of wilderness-based education and outdoor leadership.

A body of research has been conducted on the outcomes of wilderness adventure programs, especially on those offered by Outward Bound and NOLS. It is important to clarify here what is meant by outcomes. Outcomes are defined in the context of this study to mean the 
end results in participants' minds. This includes the consequences of experiencing an adventure program that can be expressed as desired consequences or benefits, as well as undesired consequences or costs. Outcomes also include personal values or ends that are perceived by participants to have come about or been reinforced from the adventure program or experiences on the program.

A literature review into the outcomes gained from adventure programs concluded that these experiences had positive effects for individuals and groups. Hattie, Marsh, Neill, and Richards (1997), which looked at 96 unique studies related to the benefits of Outward Bound programs concluded that these programs had positive effects on participants' interpersonal skills, leadership skills, sense of empowerment, self-control, independence, assertiveness, decision making skills, and self-esteem. Hattie et al. and Ewert and McAvoy (2000) examined issues related to group dynamics in adventure programs and found that they had positive effects on both group dynamics and development.

\section{Need for the Study}

A review of the literature provided a useful foundation for investigation into the outcomes of wilderness adventure programs, but a few studies found that additional research was needed to deepen the understanding concerning how and why program elements contributed towards specific program outcomes (Ewert \& McAvoy, 2000; Hattie et al., 1997; McKenzie, 2000, McKenzie, 2003). Priest (1999b) concluded that, “a descriptive base has been established as to what programs are like, what they contain, and what happens during them. However, very little research has been conducted on the relationships and influences that affect program outcomes" (p. 314). The wilderness adventure education research has essentially uncovered what 
has been referred to as a "black box", where it was widely accepted that adventure education worked, but researchers could not prove why or how (Ewert, 1983; McKenzie, 2000; Sibthorp, Paisley, \& Gookin, 2007). Sibthorp et al. found that the consequence of this black box in adventure education research was that, "many adventure programs continue to rely on anecdotal evidence and the assumption that simple participation leads to participant development without the ability to articulate the specific mechanisms through which change may occur" (p. 1).

Researchers in the adventure education field have cited the need for a longitudinal study to track the outcomes of wilderness adventure programs on participants over time (Ewert \& McAvoy, 2000; Sibthorp, 2003; Sibthorp, Paisley, \& Furman, 2008). Previous research has documented the immediate outcomes associated with participation in wilderness adventure programs, but few have documented the transference of long-term outcomes associated with these programs (Goldenberg, McAvoy, \& Klenosky, 2005; Sibthorp et al., 2008).

\section{Contribution of the Study}

This study builds on previous research on wilderness adventure education that implemented means-end theory. This includes an examination of the factors associated with participation in a ropes course program (Goldenberg, Klenosky, O’Leary, \& Templin, 2000); the outcomes and related meanings associated with completing an Outward Bound program (Goldenberg et al., 2005); and the outcomes associated with participation in an integrated wilderness adventure program (McAvoy, Holman, Goldenberg, \& Klenosky, 2006). While these studies helped establish a solid foundation for the use of means-end theory to further understand the behaviors and motivations of wilderness adventure education participants, they did not examine the transference of the long-term personal outcomes. 
In 2006 Dr. Marni Goldenberg embarked on a research study to examine the immediate and long-term outcomes experienced from participation in adventure education programs offered by Outward Bound and NOLS. This thesis is part of that long-term study, comparing the initial data collected in 2006 with the two year follow-up data collected in 2008. Tracking participant responses over time will allow researchers to measure whether participants transfer the knowledge, skills, and values obtained from their program and apply these outcomes to their lives.

\section{Purpose of the Study}

To gain a better understanding of the outcomes that individuals experience from participation in a wilderness adventure program and the effects they have on participants' lives.

\section{Objectives}

1. To gain a better understanding of the outcomes that individuals experience from participation in wilderness adventure education programs.

2. Investigate the transference of values from the wilderness adventure education program into participants' lives.

\section{Research Questions}

1. What are the attributes, consequences, and personal values that individuals retain two years after participation in a wilderness adventure program?

2. Have the values stated by individuals changed two years after participation in a wilderness adventure program? 


\section{Scope of the Study}

The initial study took place in the summer of 2006 at three Outward Bound program sites in the Rocky Mountain Region of Colorado and at one NOLS program site in the Wind River Mountains of Wyoming. Follow-up phone interviews were conducted with the original study participants during the spring and summer of 2007, 2008, and 2009. For the purposes of this thesis only the original data collected during the summer of 2006 and the two year follow-up data collected in 2008 were investigated and analyzed. Results and interpretations from the follow-up data collections in 2007 and 2009 are not represented.

The sampling frame was limited to wilderness adventure courses offered by Outward Bound and NOLS because of the highly respected status within the experiential education field that both organizations hold. Sampling these organizations also allowed researchers to investigate two different programs offering similar experiences; in terms of geographic region, course length, and course activities. The large amount of potential subjects at each base camp and similarities between the different program locations also factored in to the creation of the sampling frame. Fifteen courses from Outward Bound and 40 courses from NOLS were selected based on this convenience sampling method.

The courses sampled took place for at least seven days with many lasting two to three weeks. Participants in the courses were at least 14 years of age and represented both genders. Many courses shared activities such as expeditioning, backpacking, orienteering, rock climbing, and Leave No Trace instruction; however, each course offered a unique combination of activities and experiences. The sample size consisted of a mixture of male and female participants. Semistructured interviews were conducted with participants on a voluntary basis during the last two 
days of their course. Researchers hand-recorded participant responses to interviews on preprinted interview scripts.

The sample from the two year follow-up data collection was limited to participants from the initial data collection willing to participate in follow-up phone interviews. Semi-structured phone interviews were conducted with participants from the original study on a voluntary basis. A single interview script was the instrument utilized to document participant interviews, which was similar to the script used in the initial data collection.

\section{Theoretical Framework}

This study employed means-end theory to examine the attributes, consequences, and values associated with participation in a wilderness adventure program. Means-end theory was originally developed from the application of the personal values perspective to the marketing of consumer products (Gutman, 1982). Gutman added that the theory sought to better understand how consumers or participants felt about a particular product or service. According to Reynolds and Gutman (1988) the theory focused on the interrelationship among product and meaning at three cognitive levels of abstraction that were hierarchical in nature: attributes, consequences, and values. Reynolds and Gutman go on to state that the attributes represented the "means" by which consumers obtained desired consequences or benefits, as well as avoided undesired consequences or costs, and achieved important personal values or "ends".

Instead of treating the three elements independent of each other, means-end theory considers them as fundamentally interrelated. Gutman (1982) describes the linkages between the attributes, consequences, and values as means-end chains. Each link in the means-end chain describes how a participant's thoughts progress from either attribute to consequence or 
consequence to value so that the thought process can be followed from start to finish. A meansend chain for a wilderness adventure experience, for example, includes the attribute of rock climbing. Rock climbing can then be linked to the consequence of personal challenge, which can then be linked to the value of sense of accomplishment for having successfully completed a climb.

The application of means-end theory to wilderness adventure education can lead to a greater understanding of the meanings adventure program participants associate when experiencing a program, and the personal values that underlie their behavior. Understanding the meanings and motivations that participants associate with the experiences of the adventure program can aid researchers in drawing inferences about why and how participants experience certain values or outcomes.

\section{Data Set Comparison}

To investigate the second objective of the study, to know whether participants were transferring the values from their experience back into their lives, a quantitative procedure was needed. The statistical procedure of chi-square testing, specifically two types of hypothesis tests, a test of independence and a goodness-of-fit test, was used to see if there was a statistically significant difference in the number of times participants mentioned particular values from the initial data collection to the two year follow-up. This allowed researchers to look at all of the participants interviewed in both data collections, from both organizations sampled, and see if there was a difference in the number of times they mentioned particular values over time. 


\section{Summary}

A body of scientific research has been conducted on the outcomes experienced from participation in wilderness adventure education programs, including individual and group related benefits. What the outcomes of adventure programs are has been established, but additional research has been called for to investigate how and why these outcomes have come about. Additional research has also been called for to investigate the effects of outcomes on participants over time, after the program has ended.

The purpose of the study is to gain a better understanding of the outcomes that individuals experience from participation in wilderness adventure programs and the long-term affects these outcomes have on participants' lives. The study's objectives include gaining a better understanding of the outcomes experienced from participation in adventure programs and to determine whether participants are transferring the values gained from the program into their lives. The study will occur over a five year period; the initial data collection took place in the summer of 2006 at Outward Bound courses in the Rocky Mountains of Colorado and at NOLS course in the Wind River Mountains of Wyoming. Follow-up phone interviews were conducted with the same sampling frame in 2007, 2008, and 2009. For this thesis the focus will be on the initial and the second year follow-up data collections.

This study builds on previous research that investigated the outcomes of adventure program participants that used a similar theoretical framework. The theoretical framework is means-end theory, which helps researchers understand what the outcomes of participants are and to better understand how and why the outcomes come about. To investigate the second objective of the study, determining whether participants are transferring the values gained from the program into their lives; researchers will use the statistical procedure of chi-square testing. 


\section{Definition of Terms}

Adventure education. Adventure education is concerned with personal and interpersonal relationships among people and the provision of opportunities for growth through adventure experiences that take place in natural environments (Priest, 1999a).

Attributes. The physical aspects or characteristics that can be used to describe a product, service, or experience of the individual (Reynolds \& Gutman, 1988). Some attributes for a wilderness adventure program include the activities done while on course, the weather and environmental conditions experienced on course, and the other participants and course instructors.

Consequences. The direct result of an attribute, whether positive or negative. Negative consequences are referred to as costs or risks and positive consequences are referred to as benefits (Reynolds \& Gutman, 1988). A risk involved with a wilderness adventure program, for example, is fear or anxiety resulting from participation in certain activities or from living in the wilderness environment. A benefit from such programs could be personal growth or skills developed on a course.

Experiential education. A philosophy and methodology in which educators purposefully engage learners in direct experience and focused reflection in order to enhance knowledge (Martin et al., 2006). 
Means-end chain. A model that links together the attributes of the product or service, the consequences of those attributes, and the values important to the individual (Reynolds \& Gutman, 1988). The linkages or connections summarized by a means-end chain explain how products obtain their meaning for consumers or in the case of this study, how wilderness adventure education outcomes obtain their meaning for program participants.

Means-end theory. The purpose of means-end theory is to explain how products, services, or experiences obtain their importance to consumers. The theory focuses on the linkages between the attributes that exist in products, services, or experiences (the "means"), the consequences for the consumer of the attributes, and the personal values (the "ends") the consequences reinforce (Gutman, 1982; Reynolds \& Gutman, 1988).

Outdoor education. In outdoor education, learning is concentrated around the relationships between people and natural resources (Martin et al., 2006).

Values. Considered the desired end state for a participant. The values are the participant's end destination as they travel up the means-end ladder of abstraction from the more concrete attributes to the highly abstract value-states (Reynolds \& Gutman, 1988). Values from participation in a wilderness adventure program include fun and enjoyment of life, selfawareness, or warm relationships with others.

Wilderness adventure education programs. Generally aim to provide education and skill development, recreational enjoyment, development of moral growth, enhancement of curricular education, and assistance in personal development using the natural environment (Webb, 1999). The common thread shared by all wilderness adventure programs is exposure to elements of uncertainty, real or perceived risk, excitement, interaction with nature, and effort (Raiola \& O'Keefe, 1999). 


\section{CHAPTER 2}

\section{LITERATURE REVIEW}

The literature review is presented in section headings. The first few sections consist of definitions and explanations of experiential, outdoor, and adventure education. A history of adventure education is then presented, followed by the theoretical foundations of adventure education. The primary factors that influence the effects of wilderness adventure education programs is then discussed, followed by the research findings pertaining to the benefits gained from participation in adventure programs. The current state of research pertaining to wilderness adventure education is explained, as well as past research conducted on transference. Finally, the theoretical framework that will be used in the current study is examined along with past research that has used a similar framework.

\section{Experiential Education}

"Experiential education is a philosophy and methodology in which educators purposefully engage with learners in direct experience and focused reflection in order to increase knowledge, develop skills, and clarify values" (AEE, 2009, II 2). Experiential learning dates back beyond recorded history and remains pervasive in current society, whether formalized by educational institutions or as in informal component of daily life. In this sense, experiential learning is not an alternative approach to education, but the most fundamental and traditional form of human learning. Neill (2006) concluded that the current perception of experiential education as "different" is due less to modern developments in experiential learning than to the normalization of cognitive and didactic teaching as the mainstream educational methodology. 


\section{Outdoor Education}

Outdoor education is an experiential method of learning that takes place primarily, but not exclusively, in the natural environment. Learning in outdoor education is centered on the relationships between people and the natural environment (Martin et al., 2006). The two branches of outdoor education are environmental education and adventure education. Martin et al. concluded that environmental education is concerned with the interdependence of living organisms in an ecological system and the interactions between human society and the natural resources of an environment. Priest (1999a) concluded that adventure education is concerned with interpersonal and intrapersonal relationships through the use of adventure experiences.

\section{Adventure Education}

Priest (1999a) stated that the premise of adventure education is that change may occur in individuals or groups from direct and purposeful exposure to challenge and adventure experiences. Adventure experiences include recreational pursuits in the outdoors, such as backpacking and rock climbing, and artificial adventure environments, such as ropes courses. The adventure experience may not necessarily cause the change, but rather show a need for change. Priest argued that the purpose of adventure education is to bring about awareness of these changes.

\section{History of Adventure Education}

Early philosophy on experiential education can be traced to the ancient Greeks, notably Plato (427-347 B.C.) and his student Aristotle (384-322 B.C.). Plato and Aristotle believed that young people learn lessons of virtue best by being encouraged into adventurous situations that 
required virtues to be exercised (Hunt, 1999). Hunt found that the educator Comenius (15921670) emphasized the use of the senses in learning and that an object should be experienced before being read about. Hunt also concluded that William James, the nineteenth-century philosopher, psychologist and author of The Moral Equivalent of War, argued that adventurous situations utilizing nature as a medium were ideal substitutes to war in cultivating virtues in young people.

The organized camping movement began in the nineteenth century, using adventure and the outdoors as educational tools (Raiola \& O'Keefe, 1999). Raiola and O'Keefe added that educators began teaching through expeditions, camping and challenge activities in the United States as early as 1861 . One of the first programs using camping as part of an educational program was the Gunnery School in Connecticut for young boys (Davis- Berman, Berman, \& Capone, 1994). At the end of the academic year the entire school went on a two-week, 40-mile journey into the wilderness. The idea was to "live simply, doing their cooking and chores, swimming, fishing and participating in games, songs and stories by the camp fire" (Ells, 1986, p. $6)$.

Laura Mattoon was one of the most influential activists in the early twentieth century concerned with the instruction and personal growth of young women through the use of camping (Raiola \& O’Keefe, 1999). Mattoon was considered the “Godmother of Camping” and helped to develop the National Association of Directors of Girls' Camps, which was founded in 1910 in response to the fact that women were not allowed to join the Camp Directors Association of America.

The progressive education movement accompanied the development of outdoor and experiential education in the early 1900s (Knapp, 1994). One of the leading educators and 
intellectuals of this time was John Dewey, who applied many of the ideas of earlier philosophers of education: Plato, Aristotle, and William James, among others. "Dewey's writings, work, and teaching influenced many of the school and camping programs from the turn of the century to the present day” (Raiola \& O’Keefe, 1999, p. 48). Dewey believed that education should be concerned with living and learning through direct experience and should be directed at the whole person—physically, mentally, and emotionally (Hunt, 1999).

In the late 1920s and early 1930s many public schools started developing programs using the environment and camping to educate. One of the pioneers in this area was L.B. Sharp, who began exploring the possibilities of using education in camp settings (Raiola \& O'Keefe, 1999). Sharp started Life Camps, a camp for underprivileged city children, in 1927. Raiola and O'Keefe add that using Life Camps, Sharp took principles of teaching and learning from the classroom and transferred them to the camp setting. Sharp was one of the first experiential educators to use the term outdoor education synonymously with public school camping (Knapp, 1994).

The mid-twentieth century saw the rise of the nature study movement and conservation education. "The nature study movement rose from growing discontent with rote learning and isolation of learning from world phenomena and experiences. Nature study emphasized participants' direct experience in understanding and appreciating the natural world" (Raiola \& O’Keefe, 1999, p. 49). Raiola and O'Keefe concluded that conservation education grew out of concerns about abuse of soil, range, forest, and wildlife resources. One of its main areas of focus was the integration of conservation education into school curricula. A key figure in the conservation education movement was President Theodore Roosevelt, who dramatically increased the public ownership of lands and established the National Conservation Commission to oversee these natural areas. 
"Out of the rich history and background of conservation and nature study education developed outdoor education: education in, about and for the outdoors" (Raiola \& O'Keefe, 1999, p. 49). Raiola and O'Keefe added that the 1950s and early 1960s saw the rise of school camping and the term outdoor education started to be applied in more general terms. This concept was broadened to include not only camping experiences but those on school grounds and in the larger community as well. In 1951 Northern Illinois University established the Lorado Taft field campus and became the first university to offer outdoor education courses to their students and the surrounding community (Northern Illinois University, 2009). "These programs included elements of challenge, risk, group participation, cooperation, excitement, and skill development" (Raiola \& O’Keefe, 1999, p. 49).

The 1960s saw the rise of environmental trends encouraging people to develop an understanding of and responsibility for our natural resources (Raiola \& O’Keefe, 1999). “The word 'ecology' was on everyone's lips - even those who knew little of its meaning. The outdoor education field became a change agent for attitudes and values" (Ford, 1981, p. 46). Stuart Udall's The Quiet Crisis, Aldo Leopold's Sand County Almanac, and Rachel Carson's Silent Spring were widely read and debated concerning the human relationship with the natural environment.

From the 1960s to the 1990s the field of adventure education saw a resurgent interest in experiential learning and outdoor programs (Raiola \& O’Keefe, 1999). Kurt Hahn, founder of Outward Bound, and Paul Petzoldt, founder of the National Outdoor Leadership School and the Wilderness Education Association, have played important leadership roles in the growth of adventure education as it is known today. 
Outward Bound was founded by Hahn in 1941 in Great Britain as a training program for merchant seamen to teach them survival skills at sea in preparation for World War II and to mold them into moral, good leaders for society (Miner, 1999). Miner noted that courses were a combination of small-boat training, physical fitness training, cross-country route finding by map and compass, rescue training, an expedition at sea, a land expedition across three mountain ranges, and service to the local community. "In creating the first Outward Bound School, Hahn expanded the concept of experiential learning to include adventure experience for individuals to gain self-esteem, discover inner strength and abilities, and develop a sense of responsibility toward others" (Outward Bound History, 2009, I[ 1).

In 1962 Hahn's Outward Bound concept was introduced to America with the establishment of the Colorado Outward Bound School. Outward Bound has since become the largest and most widespread adventure education institution in the U.S. and abroad, offering courses in wilderness areas all over the U.S. and in other parts of the world, such as South America and Australia (Outward Bound Wilderness, 2009). Outward Bound USA has also established nine urban programs designed to meet the needs of inner city youth and the problems they face in large cities (Outward Bound Community, 2009).

The original values of fitness, skill, initiative, perseverance, respect, and service still form the core of Outward Bound programs today (Miner, 1999). Miner also concluded that Outward Bound has played a pivotal role in the outdoor education movement, and has helped set standards for adventure programming in terms of safety, program design, and leadership. A testament to the organization's success is the extraordinary array of Outward Bound spin-offs and adaptive programs that have taken root and deeply influenced the experiential education movement (Hirsch, 1999). 
One of the most successful of the spin-off organizations from Outward Bound is the National Outdoor Leadership School, known as NOLS. NOLS was founded in 1965 by Paul Petzoldt. Petzoldt was chief instructor for the Colorado Outward Bound School when he realized the need for better-prepared leaders for all outdoor schools and programs capable of leading others in the wilderness (Bachert, 1999). Bachert went on to state that the core curriculum of NOLS consisted of safety and judgment, leadership and teamwork, outdoor skills, and environmental studies. The delivery of this content suggested opportunities to not only be a participant but also a leader of outdoor adventure experiences. Bachert concluded that the wilderness as a classroom and the education that came with such hands-on learning stood in stark contrast to the U.S. educational system and propelled many young people to have a "wilderness experience." This demand for backcountry programs created an expanding need for qualified outdoor leaders, which became the focus of NOLS.

The current mission of NOLS is "to be the leading source of wilderness skills and leadership that serve people and the environment” (NOLS Mission, 2009, I 1). NOLS currently has schools in Wyoming, Alaska, Washington, and Arizona; as well as in international locations such as Africa, Mexico, Chile, and Canada (NOLS Courses, 2009). "NOLS is recognized as an international leader in the field of wilderness-based education and outdoor leadership" (Bachert, 1999, p. 85).

Recent history of the adventure education field has seen growth into other sectors of society. The executive challenge programming, also called experience-based training and development, emerged in the 1980s and continues to grow (Raiola \& O'Keefe, 1999). These programs use the philosophy and methods of adventure education and apply it to management 
and executives of companies around the world. Outward Bound has become a leader in developing this type programming (Outward Bound Professional, 2009).

"Wilderness therapy, now called adventure therapy, began with some of the early camping movement programs, such as the Life Camps, and became more refined with Outward Bound in the 1970s and 1980s" (Raiola \& O'Keefe, 1999, p. 51). Working with clients using a wilderness setting, adventure therapists have taken the core of adventure education philosophy and methods and applied them therapeutically to diverse groups. These groups include persons with disabilities, wilderness therapeutic groups, youth-problem behaviors, psychiatric wilderness treatment groups, and wilderness family therapy. Ewert and McAvoy (2000) found that these programs were often targeted at addressing specialized variables such as recidivism, social integration, empowerment, level of substance abuse, and mental health.

Through the passage of the Americans with Disabilities Act (1990), accessible programming for all people has increased. Although, as Raiola \& O'Keefe (1999) point out, “this area needs to be addressed in the future to make sure programming is accessible to all who desire it” (p. 51).

The risk management aspect of adventure education continues to be an important issue for the field. The 1990s saw the emergence of the Association of Challenge Course Technology, with its development of challenge course building standards, and the Accreditation Standards by the Association for Experiential Education (Raiola \& O’Keefe, 1999).

The adventure education field has also seen growth with integration into the formalized educational system. In the early 1990s Outward Bound began an initiative called expeditionary learning schools (ELS), a comprehensive K-12 educational design combining rigorous academic content and real world projects - learning expeditions - with active teaching and community 
service (Outward Bound ELS, 2009). "ELS Outward Bound is a national, non-profit organization that opens new elementary, middle, and college-oriented secondary schools, and partners with existing schools, to improve student achievement; build student character; enhance teacher practices; and instill a positive school culture" (Outward Bound ELS, 2009, II 1).

\section{Wilderness Adventure Education Theory}

Wilderness adventure education theory attracts a broad range of educational disciplines, including physiology, ecology, psychology, sociology, and political science; as well as ways of knowing such as post-modernism. It is important to investigate this interdisciplinary framework because experiential education is an interdisciplinary field and benefits from the collective wisdom of these different disciplines (Carver, 1996). An attempt to categorize the frameworks that adventure education draws its theories from is beneficial for this literature review.

\section{Behavioral Learning Theory}

Behavioral theorists argue that human development can best be understood by observing human behavior and the environmental conditions that affect that behavior (Martin et al., 2006). Many of the principles of behavioral learning theories are found in the practice of adventure education, as well as other forms of experiential learning. Kraft (1999) concluded that the idea of behavior changing according to immediate consequences is important in both classroom and nonclassroom learning environments. In a wilderness adventure setting, examples of the immediacy of consequences can be experienced through, for example, dehydration from lack of adequate water, improperly tied knots leading to a fall and injury or death, or blisters caused by ill-fitting boots. 


\section{Cognitive Learning Theory}

Cognitive learning theory addresses the process by which information is absorbed and how it can be retained (Kraft, 1999). Kraft concluded that information taken in by the senses meets the sensory register, and if nothing happens in the first few seconds significant enough to register, it is lost quickly. Piaget (1952) and his developmental theory focused on the importance of active learning and concrete experiences in the developmental stages of cognitive growth. Paiget's work provides some important implications for experiential educators, such as the active nature of all learning, and children learn best from concrete examples. Piaget concluded that even adolescents and adults need concrete examples to develop new physical knowledge.

Adventure educators often pride themselves on challenging all the senses of their students, and while the evidence is limited, it appears that memories of the experiences that make up adventure programs are retained longer than less profoundly moving experiences found in the classroom (Kraft, 1999). Kraft also warned that what is learned or retained from adventure programs has not been carefully researched and it is wise for experiential educators to limit their claims to the benefits of participation in adventure programs.

\section{Social Learning Theory}

Social learning theory is based on the basic principles of behavioral learning theory, but suggests that humans also learn by modeling or imitating other's behaviors (Bandura, 1969). An individual may pay close attention to a modeled behavior, store the information about it, and later retrieve it from memory. In wilderness adventure education programs, the consequences of the natural environment shape much of the learning, but social learning occurs through modeling by course instructors and through the group experience that is a vital part of these programs. 


\section{The Theory of Multiple Intelligences}

According to Gardner (1983), the human capacity to learn and problem solve, referred to often as intelligence, came to be defined in modern society in terms of linguistic and logicalmathematical intelligences to the exclusion of other forms of intelligence. Gardner proposed eight distinct criteria for intelligence and seven human competencies. The premise behind Gardner's work is that humans learn in different ways and through distinct mediums. The eight intelligences included verbal-linguistic, visual-spatial, bodily-kinesthetic, naturalistic, musicalrhythmic, mathematical-logical, interpersonal, and intrapersonal. The bodily-kinesthetic intelligence refers to knowledge-building through feedback from physical activity. This intelligence has provided solid research rationale for bodily-kinesthetic activities often used in outdoor education. Two other intelligences hypothesized by Gardner, interpersonal and intrapersonal, have also provided solid rationale for many personal and group activities that are vital to outdoor education programs (Kraft, 1999).

\section{Nature Theories}

Nature-based theories emphasize the importance of human interaction with the natural world and their understanding of their place in it. A unique feature of adventure education is the direct engagement with an activity in a natural environment. Research in health, medicine, and psychology appear to support the proposition that nature has inherently positive effects on the physical and psychological well-being of humans (Neill, 2007a). Hattie et al. (1997) found surprisingly little outdoor education theory draws from theorizing about the role of the natural environment in understanding the processes and outcomes of outdoor education programs. 
Wilson (1984) hypothesized that humans evolved as creatures deeply enmeshed with the intricacies of nature, and that we still have this connection with nature ingrained in our genotype. Wilson coined the term "biophilia," referring to a human's love of living things, or innate affinity with nature. The biophilia theory, though controversial within scientific research, is supported by studies that reveal how positively humans respond to the natural environment (Frumkin, 2001; Ulrich, 1984).

Psycho-evolutionary theory proposes that human behaviors, attitudes, emotions, and cognitions adopted during human evolution (Neill, Gray, Ellis-Smith, Bocarro, Sierra, \& Desai, 2004). Neill et al. stated that outdoor education emerged out of two forces, human evolutionary history and the rapid cultural shift away from natural living environments to artificial living environments. Neill et al. concluded that outdoor education emerged in post-industrial western societies as a compensatory effort by humans to re-engage with their indigenous heritage and inner indigenous nature.

As a setting for outdoor education, the role of the natural environment was perhaps most insightfully articulated by James (1980). James describes the philosophical debate that took place among the staff at the Colorado Outward Bound School. The debate pitted the early mountaineer-type instructors against the formal-education type instructors who insisted that wilderness adventure experience needed to be accompanied by direct psychological processing in order for participants to achieve the full benefits of an Outward Bound program.

The mountaineering side of the debate argued that well-designed, genuine adventure in the wilderness can give the students a good experience; elaborate verbalization and testing in a controlled group process is not needed in order for learning to occur. The point they were 
making was not precisely that the mountains do the teaching, rather it was the Outward Bound training sequence used in an effective way that helped people to learn (James, 1980).

The formal-education side of the debate recognized the uniqueness of the natural learning environment provided by the mountains, but also looked for a connection between the intensity of that learning environment and life back home for participants. This is reflected by the statement coined by Outward Bound instructors of teaching through the mountains and not for the mountains. The new age educators were not denying that challenge and adventure were the bedrock of Outward Bound programs; they were not seeking psychological processing and reflection instead of action, but in addition to it (James, 1980).

The debate was important because it highlighted the idea of the practical application and transference of outdoor education to a person's life. Neill (2007a) found that a limitation of the experiential, human development, and nature theories was their lack of practical application to participant's lives back home. Neill goes on to state that these limitations led outdoor education theorists and programmers to develop their own practical-theoretical programming models.

\section{Practice-Based Multi-Dimensional Theoretical Based Models}

Practical-theoretical programming models concentrate on what outdoor education organizations and theorists believe are vital combinations of factors for a successful outdoor education experience. Neill (2007a) found that practical-theoretical models generally emphasize the role of the individual, the role of the activities and their sequential order in the program, the role of the environment, the role of the instructors, and the role of the group.

Gager (1977) developed a model of the experiential learning process in which the learner was placed in a demanding situation where action and decision-making were required. Mastery 
of a new skill was necessary, which helped satisfy ego needs and self-esteem. This experience was then followed by a similar challenge. The last step allowed the learner to reflect on their performance and connect the experience to a broader range of experiences. Rock climbing, for example, places one in a demanding situation that requires action and on-the-spot decision making. The development of skills needed to climb can lead to feelings of accomplishment. If and when the challenge is accomplished, individuals reflect on what they learned about themselves and how it could be applied to other life experiences.

Kolb's (1984) experiential learning cycle also begins with experience but expands upon the Gager model by adding that the observations are assimilated into a "theory" from which new implications for action can be deduced. These implications or hypotheses serve as guides for new experiences. For example, the experience of camping can be used to formulate theories on how to build a better campsite. This means that one experience can be used as a basis for future experiences.

A well cited theoretical outdoor education model is the Outward Bound process model, sometimes referred to as the Walsh and Golins model (Walsh \& Golins, 1976). The Walsh and Golins model proposes a series of seven processes to explain the apparent power and effects of Outward Bound programs (see figure 2.1). 


\begin{tabular}{|c|c|c|c|c|c|c|}
\hline $\begin{array}{c}\text { A } \\
\text { learner }\end{array}$ & is placed into & $\begin{array}{c}\text { Prescribed physical } \\
\text { environments }\end{array}$ & and into & - $\begin{array}{c}\text { Prescribed social } \\
\text { environments }\end{array}$ & then given a & $\rightarrow \begin{array}{c}\text { Characteristic set of } \\
\text { problem-solving tasks }\end{array}$ \\
\hline $\begin{array}{c}\text { (who is motivated } \\
\text { and ready) }\end{array}$ & & $\begin{array}{l}\text { (that are contrasting } \\
\text { and novel, } \\
\text { stimulating, straight- } \\
\text { forward, and neutral } \\
\text { or impartial) }\end{array}$ & & $\begin{array}{l}\text { (of small group social } \\
\text { units with } 7-15 \text { people } \\
\text { and with collective group } \\
\text { consciousness, objectivi- } \\
\text { ty, autonomy, individuali- } \\
\text { ty, conflict resolution, } \\
\text { trust support, and reci- } \\
\text { procity) }\end{array}$ & & $\begin{array}{l}\text { that utilize all learning domains } \\
\text { and are prescriptive or } \\
\text { organized; incremental, } \\
\text { progressive, or sequential; } \\
\text { concreteor or recognizable; } \\
\text { manageable, solvable, or } \\
\text { achievable; consequential or } \\
\text { worthwhile; and holistic and } \\
\text { complementary) }\end{array}$ \\
\hline
\end{tabular}

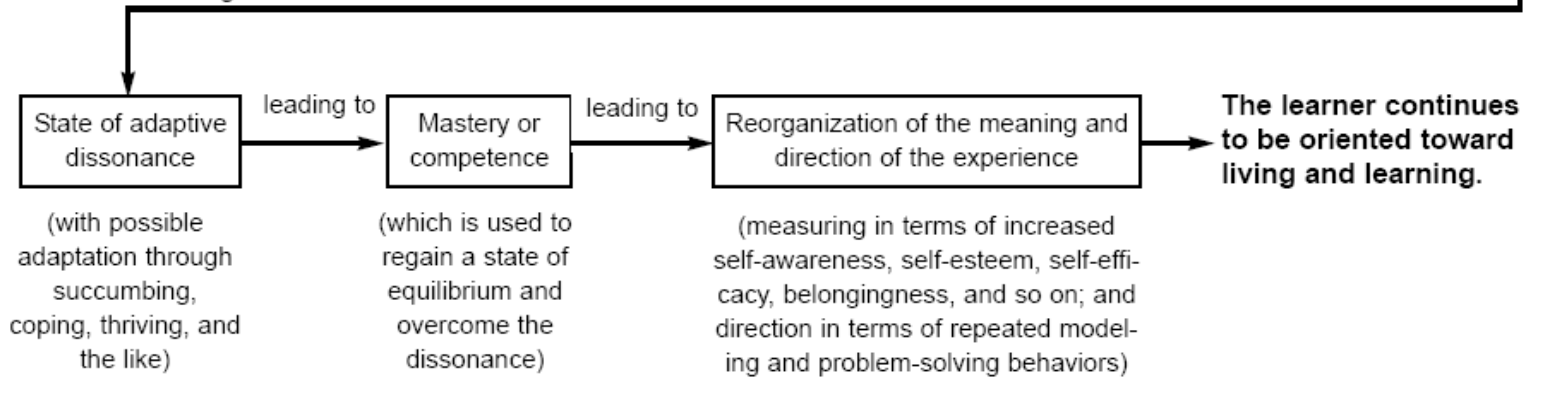

Figure 2.1. Outward Bound Process Model (from Priest \& Gass, 1997, p. 140)

This model suggests that the learner will continue to be positively oriented to further learning and development experiences, a concept known as transfer.

The Outward Bound model has changed over time. The first generation model, mentioned in the previous section, known as the "mountains speak for themselves" curriculum, involved completion of the experience as facilitating change in participants. The second generation model built on the "mountains speak for themselves" model by putting more emphasis on group processing and discussions (Bacon, 1990). Bacon also found that the third generation model was referred to as the metaphoric model, which provided a metaphor for each activity to daily life back home.

McKenzie (2003) proposed a model that added a more detailed understanding of relationships between course components, student characteristics, and course outcomes to the Outward Bound process model. This alternative model included course activities, service, and 
instructors to the components already employed by the Outward Bound model. The McKenzie model also deemed characteristics of the learner (i.e., age, gender, background) as important considerations, along with the motivational level of the learner (see figure 2.2).

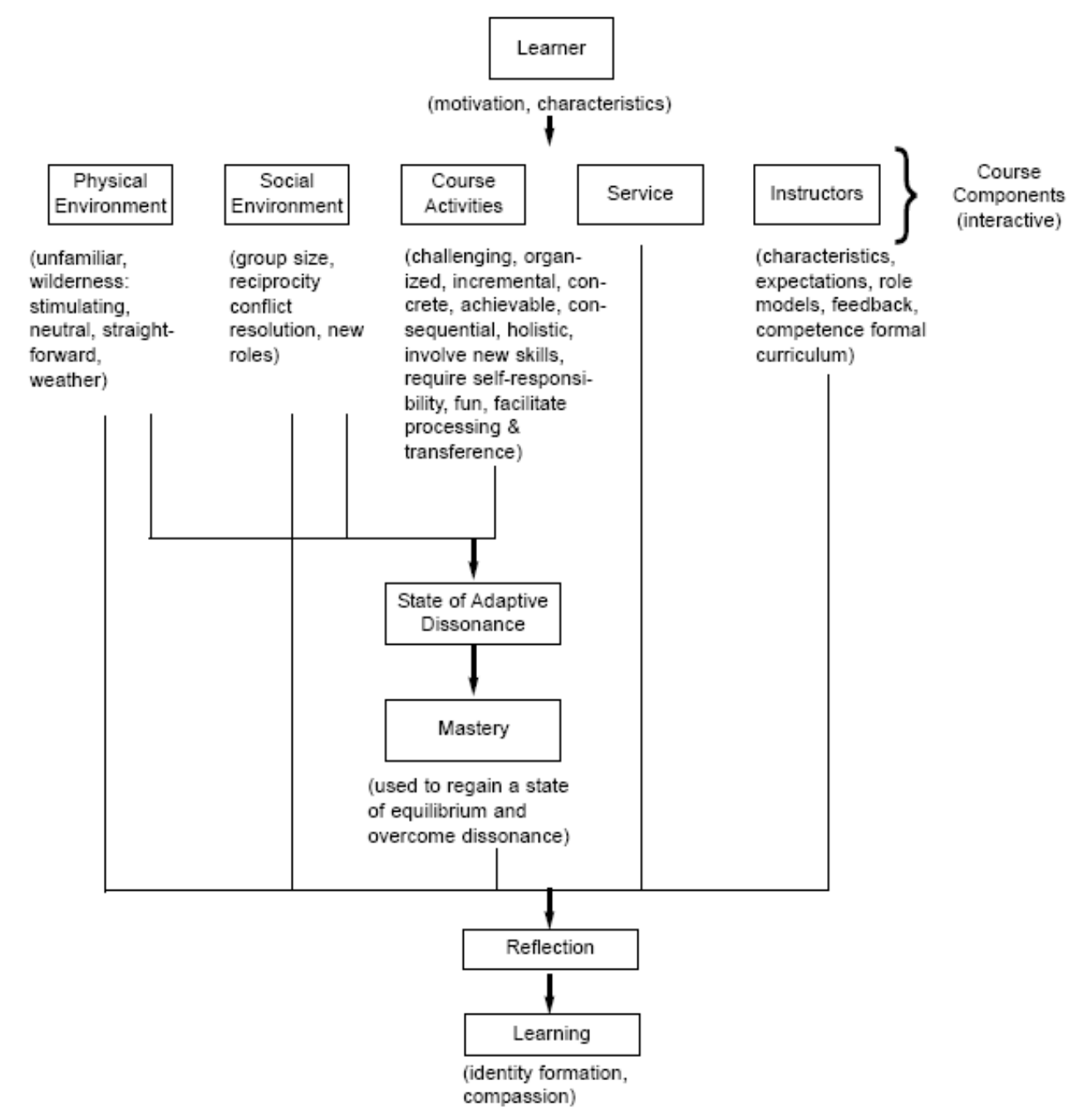

Figure 2.2. McKenzie Processing Model (from McKenzie, 2003, p. 20)

Factors That Influence the Effects of Outdoor Education Programs

Outdoor education programs vary widely in philosophy, instructional method, and activities, so it can be difficult to pinpoint the "key factors" that influence program outcomes. 
Neill (2007b) proposed a list of twelve factors as the main determinants of an effective program. The first factor focused on individual differences, including gender, age, personality, readiness for change, fitness, and motivation. Neill concluded that the single biggest factor in determining a participant's experience on course was their personal history.

Neill (2007b) stated that organizational philosophy and culture was the second factor and gave rise to program design, training of instructors, and communication with participants. The focus of each particular wilderness adventure program depends on how each program chooses to serve its intended audience. Specialized groups such as those for women only, persons with disabilities, and therapeutic groups have different program goals, group organization and structure, and participant behaviors and attitudes than other wilderness groups and programs. These types of programs often target specialized goals and objectives that can be very different from the typical Outward Bound or NOLS program (Ewert \& McAvoy, 2000).

Neill (2007b) found that the third factor involved the use of experiential and consequential problem-solving tasks, offering hand-on, and concrete tasks with real-world constraints. Priest and Gass (1997) found that this factor allowed for freedom to make mistakes which have clear, natural ramifications. Dramatic activity in a novel context is the fourth factor which utilizes unique wilderness setting and provides compelling, challenging, and adventurous activity.

Theory-based, principle-driven, customized, holistic program structure is the fifth factor which customizes program design to meet unique needs of participants, and also makes clear use of good design principles (Neill, 2007b). Neill goes on to state that carefully selected and trained leaders is the sixth factor; the facilitation techniques of those leaders is the seventh factor; and group development, processes, and dynamics make up the eighth factor. The ninth factor is 
programming for transferability, including teaching skills directly applicable to everyday life and looking for metaphoric structures that relate back to home life.

The tenth factor involves the length of the program (Neill, 2007b). Longer programs have been found to be more effective. Neill concluded that although the relationship between length of program and effect was significant and positive, it appeared to be a relatively small effect. Environmental and logistical events make up the eleventh factor. Neill states that these events normally play an insignificant part in determining outcomes when things go according to plan, but it is not uncommon for events to occur outside of the group's control. Some of these unplanned events provide experiences which can prove beneficial, such as group bonding arising from an emergency on course. The last factor proposed is program modality. Neill found that no clear differences in outcomes have been found between different program modalities (i.e., landbased vs. water-based programs).

\section{Benefits From Participation in Wilderness Adventure Programs}

Ewert and McAvoy (2000) in a state-of-knowledge paper investigating the benefits of wilderness adventure programs found that since the early 1970's wilderness was being used extensively to help individuals and groups to grow. Ewert and McAvoy also concluded after an examination of the variable of self-systems (i.e., self-concept, self-esteem, and self-confidence) that a pattern had developed showing positive and beneficial change for individuals from participation in wilderness adventure programs. In a separate study, Outward Bound programs were found to be an effective intervention for enhancing multiple dimensions of self-concept and an internal locus of control (Marsh, Richards, \& Barnes, 1986). Outward Bound programs were also found to have positive effects on participants' interpersonal skills, leadership skills, sense of 
empowerment, self-control, independence, assertiveness, decision making skills, and self-esteem (Hattie et al., 1997).

Self-efficacy, which has roots in social learning theory, is the perception of what we as individuals believe we can or cannot do (Martin et al., 2006). Propst and Koessler (1998) found that self-efficacy improved for participants in a NOLS wilderness adventure program immediately after the program and one year later. Kellert (1999) found increased interest in learning, physical and mental fitness, positive behavioral changes, and a stronger commitment to conservation in participants from courses offered by Outward Bound, NOLS, and the Student Conservation Association.

Research examining issues related to group dynamics and development in wilderness adventure programs found that these programs had positive effects on both group dynamics and development (Ewert \& McAvoy, 2000; Fielding \& Hogg, 1997). Group development was found to have been strengthened due to participation in an Outward Bound course (Ewert \& Heywood, 1991). Oakes, Haslam, Morrison, and Grace (1995) reported that an Outward Bound group that did not previously know each other perceived each other as more alike than different as they progressed through their course. Group characteristics such as reciprocity, cohesion, and trust were found to contribute to the overall group effectiveness in an Outward Bound wilderness adventure program (McKenzie, 2003).

\section{Current State of Research}

While this body of research has provided a useful foundation for investigation into the outcomes and benefits of wilderness adventure programs, several have noted that additional research is needed to deepen the understanding concerning how and why program elements 
contribute to specific program outcomes (Ewert \& McAvoy, 2000; Hattie et al., 1997;

McKenzie, 2000; McKenzie, 2003). Priest (1999b) concluded that, “a descriptive base had been established as to what programs were like, what they contained, and what happened during them. However, very little research had been conducted on the relationships and influences that affected program outcomes" (p. 314). Priest went on to state that inquiry had jumped to predicting changes in human behavior, and trying to prove the changes were a result of the program. Priest concluded that the predictions often failed due to poor experimental design and shaky methodology resulting from a lack of understanding of the relationships and influences that affected the outcomes.

The wilderness adventure education research uncovered what had been referred to as a black box where it was widely accepted that adventure education worked, but researchers could not prove why or how (Ewert, 1983; McKenzie, 2000). Sibthorp et al. (2007) found that the consequence of this black box in adventure education research is that "many adventure recreation programs continue to rely on anecdotal evidence and the assumption that simple participation leads to participant development without the ability to articulate the specific mechanisms through which change occurs" (p. 1). Unable to prove why or how their programs are effective, the adventure education profession sits on the fringes of the United States educational system (Priest, 1999b). Priest went on to argue that more research is needed to demonstrate the effectiveness of wilderness adventure programs and to establish credibility in the larger disciplines of academia.

Priest (1999b) summed up the areas of study still in need of investigation: "what transfers, how much of it, for how long, and because of what program elements or barriers" ( $\mathrm{p}$. 315). Long-term and follow-up studies are seen as necessary to better understand the 
transference of benefits and outcomes on participants over time, after their experience has ended (Ewert \& McAvoy, 2000; Goldenberg et al., 2005; Hattie et al., 1997; Priest, 1999b).

\section{Study of Transference}

The concept of transference is at the heart of the debate concerning the effectiveness of wilderness adventure education programs as a viable and reliable form of education. As Gass (1999) stated rather bluntly, "the true value or effectiveness of the program lies in how learning experienced during adventure activity will serve the learner in the future" (p. 227).

Much of the research on transference has examined the retention of specifically targeted outcomes after course completion. Ten separate Outward Bound courses studied in Australia were found to be effective interventions for enhancing multiple dimensions of self-concept (Marsh et al., 1986). Marsh et al. concluded that an internal locus of control for program participants and these changes were maintained eighteen months after the program. Propst and Koessler (1998) found significant improvements in self-efficacy scores regarding wilderness skills competence with participants in month long NOLS courses in Wyoming both at the end of the course and one year after completion. Perceived increases in self-efficacy gained from participation in Outward Bound courses in Minnesota were found to have transferred into participants' lives six months after course completion (Paxton \& McAvoy, 2000). Kellert (1999) found that the majority of participants of programs offered by Outward Bound, NOLS, and the Student Conservation Association studied viewed their experience as exerting great if not greater impact six months after the program ended.

Sibthorp, Paisley, and Furman (2008) found that very little research has examined the impact from programs years after completion. Sibthorp et al. conducted a study of NOLS alumni. 
Participants were interviewed one, five, and ten years after their course completion. Sibthorp et al. identified 17 areas learned during the course and deemed relevant years after the course. These areas included a greater appreciation of nature; desire to be in the outdoors; outdoor skills; ability to get along with different types of people; ability to serve in a leadership role; and selfconfidence. It is worth noting that different individuals were interviewed from each year in this study, compared to the other studies mentioned where the same individuals were interviewed during their experience and after their experience. Sibthorp et al. also found no significant differences by year studied.

Prior research on transference has laid a foundation to better understand the outcomes that individuals gain from adventure education programs and apply to their everyday lives. But very little research has investigated the transference of program outcomes on participants' lives after a significant amount of time has passed. Sibthorp et al. (2008) found that a major challenge of documenting and studying the transference of learning in adventure education is that the majority of the transfer content or context is occurring in dissimilar situations or contexts than that in which the learning took place, a concept named "far" transfer.

\section{Theoretical Framework}

A theoretical framework provides structure and boundaries in which to conduct research. The framework is used to hypothesize, understand, and give meaning to the relationships among the factors that influence, affect, or predict the outcomes or events studied (Ennis, 1999). The theoretical framework guiding the present study is means-end theory. 


\section{Means-End Theory}

Means-end theory was originally developed from the application of the personal values perspective to the marketing of consumer products (Gutman, 1982). Gutman also noted that means-end theory sought to better understand how consumers or participants felt about a particular product or service. Gutman proposed that consumer behavior is value-driven and those values ultimately influence product choices. The theory focuses on the interrelationship between product and meaning at three cognitive levels of abstraction that are hierarchical in nature: attributes, consequences, and values (Reynolds \& Gutman, 1988).

According to means-end theory, attributes represent the means by which consumers obtain desired consequences and benefits, as well as avoid undesired consequences or costs, and achieve important personal values, or ends (Reynolds \& Gutman, 1988). Means-end theory employs a laddering method, which enables the individual to travel up the means-end ladder of abstraction from the concrete attributes to the highly abstract value-states (Gutman, 1982). Laddering enables the individual to define personal values in their own terms and facilitate an inductive perspective to understanding values and behavior, rather then into predetermined value categories used in traditional quantitative methods (McIntosh \& Thyne, 2005).

Instead of treating the three elements independent of each other, means-end theory considers them fundamentally interrelated. The linkages between the attributes, consequences, and values are described as means-end chains (Gutman, 1982). Gutman goes on to state that each link in the means-end chain described how a participant's thoughts progress from either attribute to consequence or consequence to value so that the thought process is clearly followed from start to finish. The means-end approach connects the prominent attributes of a destination, product, or interaction to an individual's personal values (McIntosh \& Thyne, 2005). 


\section{Values}

Revealing the highly abstract values of the sample participants in this study was a key to understanding whether these participants learned the lessons, experiences, and skills from the adventure program and whether they transferred this knowledge into their lives. Understanding prior social classifications of values was important to understanding how to categorize sample participants' statements into specific values. Rokeach (1973) defines a value as, "an enduring belief that a specific mode of conduct or end-state of existence is personally or socially preferable to an opposite or converse mode of conduct or end-state of existence" (p. 5).

Nine core values were identified and are referred to as the List of Values (LOV), developed to better understand how people used values to adapt in their social environments, how people used values to equilibrate themselves with the pressures they faced, and how people with different values fared in life (Kahle, 1983). According to Bearden, Netemeyer, and Mobley (1993), "the LOV was developed from theoretical approaches to the study of values proposed by Maslow's (1954) hierarchy of values, Rokeach's (1973) 18 terminal values, and the research of Feather (1975) and Veroff, Douvan, and Kulka (1981)” (p. 95). Kahle's study of 2,264 Americans found the LOV to be significantly correlated with measures of well-being, self, mental health, and adaptation to society. The List of Values (LOV) includes: sense of belonging, excitement, warm relationships with others, self-fulfillment, being well respected, fun and enjoyment of life, security, self-respect, and sense of accomplishment.

\section{Past Means-End Studies}

The majority of the initial research using mean-end theory focused on marketing and consumer choice research. Early means-end studies investigated brand management and 
advertising strategy development (Gutman, 1982; Olson \& Reynolds, 1983; Reynolds \& Gutman, 1988). The use of the theory was expanded to examine consumer choice in broader social marketing issues such as recycling behavior (Bagozzi \& Dabholkar, 1994), health care policy (Roth, 1994), weight loss goals (Pieters, Baumgartner \& Allen, 1995), and presidential elections (Bagozzi \& Dabholkar, 2000).

Means-end theory first appeared in the field of outdoor recreation with a study of ski destination choices (Klenosky, Gengler, \& Mulvey, 1993). Consumer selection of tennis rackets (Mulvey, Olson, Celsi, \& Walker, 1994), tourist selection of interpretive state park programs (Klenosky, Frauman, Norman, \& Gengler, 1998), greenway trail usage benefits and values (Frauman \& Cunningham, 2001), and push and pull factors in spring break travel decision making for undergraduate students (Klenosky, 2002) are some other recreation based means-end studies.

\section{Means-End Theory and Wilderness Adventure Program Outcomes}

Goldenberg et al. (2000) were the first to use the means-end approach to investigate the benefits and outcomes from participation in an outdoor education activity, specifically in a ropes course program. The relationships among the highly abstract values found in participants suggested that the ropes course programs examined in the study helped participants learn how to work together to accomplish given tasks, which in turn helped them to feel fulfilled and happy about themselves.

The means-end approach was also used to identify and compare the linkages among the attributes, consequences, and values of participants to determine if there was a measurable difference in meaningful involvement between the Challenge by Choice and Inviting Optimum 
Participation approaches to ropes course program design and delivery (Haras, 2003). Haras concluded that the findings indicated that ropes course program design and delivery could be manipulated to provide selected benefits and facilitate participant experiences of meaningful involvement.

The means-end approach was extended to an examination of the outcomes associated with participation in an Outward Bound program and differences in five key program elements: rock climbing, interactions with others, expeditioning, camp craft skills, and the solo experience (Goldenberg et al., 2005). Goldenberg et al. presented an understanding of the outcomes perceived by program participants and how these outcomes contribute to the development and reinforcement of personal values. Goldenberg et al. also found that these values were perceived to positively impact participant's lives after the experience was over.

The means-end approach was also applied to an examination of the outcomes associated with participation in an integrated wilderness adventure program, which combined participants with disabilities and those without (McAvoy, Holman, Goldenberg, \& Klenosky, 2006). Results showed that persons with disabilities received and used a range of benefits from the adventure program and the outcomes had a lasting effect on their lives. McAvoy et al. investigated transference of outcomes to participants' lives; however, the number of participants' interviewed after their experience was small.

\section{Summary}

Experiential education is a philosophy and methodology that dates back beyond recorded history and remains pervasive today. Outdoor education is an experiential method of teaching and learning; adventure education is a form of outdoor education. Modern adventure education 
has been influenced by the philosophical beginnings of experiential education; the organized camping movement of the $19^{\text {th }}$ century; the progressive education movement of the early $20^{\text {th }}$ century; the conservation education and nature study movements of the mid $20^{\text {th }}$ century; the formation of outdoor education as a field of study that grew out of the conservation and nature study movements; and the rise of environmental education that came out of the 1960s.

Adventure education pioneers such as Kurt Hahn and Paul Petzoldt, along with the organizations they founded, Outward Bound and NOLS have also had a profound effect on modern adventure education. Modern adventure education has drawn from a broad range of academic disciplines that have contributed scientific theory and theoretical based programming models to the development of the field.

It can be difficult to pinpoint the "key factors" that influence adventure program outcomes due to differences in philosophy, instructional method, and activities. But key factors which are thought to influence the outcomes were presented, along with the benefits, both for individuals and groups, gained from participation in wilderness adventure programs.

Prior research has provided evidence into what the outcomes from participation in adventure programs are, but continued research into how and why outcomes are achieved has been called for. Prior research also points to further investigation into the transference of outcomes from adventure program to everyday life and the long-term effect on participants.

Means-end theory is the theoretical framework of the current study and will help researchers gain a better understanding of not only what the outcomes from adventure programs are, but how and why the outcomes come about. A few studies have examined the outcomes associated with participation in adventure programs using means-end theory, but none have looked at the long-term transference of outcomes into participants' lives. 


\section{CHAPTER 3}

\section{METHODOLOGY}

The purpose of this study is to gain a better understanding of the outcomes that individuals experience from participation in a wilderness adventure program and the effects they have on participants' lives. This chapter reviews the scope of the study; the description of the subjects sampled; instruments used in data collection; procedures used to measure the data; methods used to analyze the data; and validation criteria for the methods used.

\section{Scope of the Study}

This study is part of a longitudinal study, consisting of data collection over a five year period of time. The original data collection took place in the summer of 2006 when researchers interviewed participants of Outward Bound and NOLS programs. Follow-up phone interviews were conducted with the original participants in 2007, 2008, and 2009. Follow-up interviews are also planned for 2010. For the purposes of this thesis only the original data collected during the summer of 2006 and the two year follow-up data collected in 2008 will be investigated and analyzed. Results and interpretations from the follow-up data collections in 2007 and 2009 will not be represented.

\section{Description of Subjects}

\section{Initial Data Collection}

The sampling frame was limited to participants of Outward Bound courses in the Rocky Mountains of Colorado and NOLS courses in the Wind River Mountains of Wyoming. Outward Bound participants came from a total of 15 courses, eight from Leadville, $\mathrm{CO}$, three from 
Silverton, CO, and four from Marble, CO. NOLS participants came from a total of 40 courses collected at a program site near Lander, Wyoming. Courses sampled were limited to those that were seven days or longer. The sample consisted of male and female participants, aged 14 and over. Overall 510 students participated in the study (Outward Bound $=162 ;$ NOLS $=348$ ).

The sampling frame was limited to wilderness adventure courses offered by Outward Bound and NOLS because these organizations were pioneers in the field of wilderness-based education and are still well respected within the field. Sampling these organizations also allowed researchers to investigate two different programs offering similar experiences; in terms of geographic region, course length, and course activities. Although many courses shared certain activities such as expeditioning, backpacking, orienteering, rock climbing, and Leave No Trace instruction, each course offered a unique combination of activities and experiences. Researchers focused on Outward Bound courses in Colorado and NOLS courses in Wyoming due to the large amount of potential subjects at each base camp and the relatively close proximity of the program locations.

Subjects were selected using a convenience sampling method. Semi-structured interviews were conducted with participants on a voluntary basis during the last two days of their course. Researchers remained on-site at the base camp throughout these course ending dates and approached subjects during idle time to request an interview. Many interviews were conducted during meal times and gear sorting and cleaning periods. Participants were greeted by the researchers with an explanation of the research being conducted. Most interviews took place in the presence of other group members from the course, but some were conducted in a one-on-one setting. Participants age 18 or over were given a consent form for their records; minors were identified from a list of pre-course completed parental consent forms. Participants were given the 
opportunity to ask any questions about the research or use of the data prior to beginning the interview.

\section{Two Year Follow-up Data Collection}

The sampling frame was limited to participants that were contacted and willingly agreed to follow-up phone interviews two years after the initial study. Phone interviews were completed based on the convenience of the participants to complete the interview. The graduate researcher conducting the interviews would call a potential participant three times in a two week period in order to conduct an interview. If the participant could not be reached after three attempts, then the researcher would stop and try again at a later date. For every ten attempts to contact a participant, the researcher would reach one. Participants that were reached were willing to be interviewed eight out of ten times or $80 \%$. Reasons that participants declined to be interviewed included being too busy, not having enough time, and not interested in participating. In total 197 participants completed interviews (Outward Bound $=89$; NOLS $=108$ ). It should be noted that three interviews that were completed could not be used due to a lack of an identification number that was used to keep track of participants from the original data collection. This was a result of a recoding error that occurred from the original data collection to the two year follow-up.

\section{Instruments Used in Data Collection}

\section{Initial Data Collection}

Researcher's hand-recorded participant responses on a pre-printed interview script (see appendix A). The interview script was adapted from a questionnaire originally designed for a study of Outward Bound course outcomes (Goldenberg, 2002). The first section of the script 
identified participant descriptive statistics, including age, gender, ethnicity, and previous Outward Bound or NOLS involvement. The next section asked for information about the subject's experiences on course, including duration of the course and activities participated in on course. The last section of the interview focused on collection of means-end data. Subjects were asked to identify three to four of their favorite course components. Once subjects assembled their list of components, they were asked a series of questions for each stated component using the laddering technique.

\section{Two year Follow-up Data Collection}

The follow-up data collection utilized a single interview script similar to the one used in the initial data collection (see appendix B). The first section of the script asked participants to remember three or four of the most meaningful components or experiences from their course. Once the participants assembled their short list of meaningful components or experiences, they were asked a series of questions using the laddering technique for each stated component or experience. The last section of the script identified current participant descriptive statistics, including age, email, occupation, and whether they would recommend an OB or NOLS program to people they know. An audio recorder was used after receiving consent from the participant to record the interview. The purpose of the recorder was to aid the interviewer in recalling information from the interview. 


\section{Description of Procedures}

\section{Means-End Analysis}

Means-end data was collected using a qualitative research technique known as laddering. Laddering involved asking a series of open-ended questions that first asked the respondent to identify the attributes of a product, or as in the present study, the outcomes that were important to them that they received from participating in a given activity. The respondent is then asked why a particular outcome was important. The response given was then the focus of the next, "why is that important?" question. This process of asking, "Why is that important?" continued for each response given until the respondent could no longer provide a meaningful answer (e.g., the response is "I don't know," or "It just is..."). The procedure is called laddering because it forces the respondent up the "ladder of abstraction," bridging relatively concrete concepts at the outcome or benefit level to more abstract concepts at the value level (Reynolds \& Gutman, 1988). This process of laddering responses and associating course components was repeated for each of the components that the subject had identified in the interview. Each ladder represents a participant's thought progression from the attribute (course component) to its associated consequences and values.

\section{Comparison of Data Sets}

A categorical statistical procedure was implemented to test whether a significant difference existed between program type, Outward Bound and NOLS, and the number of times the sample participants mentioned particular values over time, from the original data collection to the second year follow-up data collection. Specifically a Pearson's chi-square test of independence was used to cross tabulate the program type with each change in a particular value. 
A test was run for all eight values from the means-end outcomes list. As a follow-up procedure a chi-square goodness-of-fit test was conducted for all eight values to test a hypothesis about how the data was distributed across the three categories of change.

\section{Data Analysis}

\section{Means-End Analysis}

Once data were collected, they were transcribed into LadderMap, the primary software package used to analyze means-end data (Gengler \& Reynolds, 1995). The data were separated into three categories to perform a means-end analysis: laddering data, demographic data, and contact information. Contact information and participant demographic data were described previously. Analysis of the laddering data involved several steps. In the first step, the data are reviewed by the researchers, and content codes are developed based on participants' responses to the laddering process. Content codes are developed based on phrases and key words that emerged from the data. Codes are created for three categories: attributes, consequences, and values (Reynolds \& Gutman, 1988).

In the second step of data analysis the coded ladder categories are aggregated and used to develop an implication matrix, i.e., an asymmetric matrix that summarized the number of times each concept was associated with each of the other concepts in the respondents' ladders, determining the dominant connections between the key attributes, consequences, and values. The implication matrix enabled the researchers the ability to summarize the means-end data by subgroups (Reynolds \& Gutman, 1988).

The third step in data analysis is the development of hierarchical value maps (HVMs) which are based on the relationships identified in the implication matrix. The HVM provide a 
graphical summary that illustrates the relationships and links between the attributes, consequences, and values (Reynolds \& Gutman, 1988). The HVM do not illustrate every link that is generated across participant responses, but rather summarizes the key linkages that emerged across all participant responses.

HVMs can provide useful insights into the process that leads participants from the attributes of an experience, to the consequences of those attributes, and finally to the values obtained from that experience. HVMs can provide comparison between different groups of participants, different activities done on the course, or with a variety of other factors. Knowing what the attributes, consequences, and values are for participants in an adventure program and more importantly the connections between these variables can only help researchers in understanding how and why these outcomes came about.

\section{Comparison of Data Sets}

For the chi-square statistical procedures categorical variables were created for the type of program sampled and for the change in the number of times sample participants mentioned particular values from the original to the second year follow-up data collection periods. For the variable of change in value over time, three categories were created: 1) if a participant mentioned a value fewer times in the second year follow-up data collection then it was categorized as a negative change; 2) if a value was mentioned the same amount of times between the two data collections then it was categorized as no change; and 3) if a value was mentioned more times in the second year follow-up data collection then it was categorized as a positive change. See appendix $\mathrm{C}$ for a complete list of the values. 
A Pearson's chi-square test of independence was conducted to cross tabulate the program type with each change in a particular value. Because there were eight values, eight tests were run, and the hypotheses for each test were as follows:

$H_{o}$ : No relationship exists between program type and change in value.

$H_{1}$ : A relationship does exist between program type and change in value.

As a follow-up procedure a chi-square goodness-of-fit test was conducted for all eight values to test a hypothesis about how the data was distributed across the three categories of change. The hypotheses for the goodness-of-fit tests were as follows:

$H_{o}$ : Participants were equally likely to report a negative, positive, and no change in values tested. $H_{1}$ : Participants were not equally likely to report a negative, positive, and no change in values tested.

\section{Validation Criteria \\ Means-End Analysis}

In the first step of data analysis content codes were developed based on participants' responses to the laddering process. The content codes were then tested in a blind review by an independent coder to determine intercoder reliability. If the blind test was at least an $80 \%$ match with the researchers' content codes then they were deemed valid. If there was not an $80 \%$ match then researchers went back and "cleaned up" or clarified their original content codes. When the codes were deemed sufficiently re-worked, another blind test was undertaken by a neutral third party. This process continues until $80 \%$ intercoder reliability is reached. The original data set was tested by an independent coder and resulted in $87 \%$ reliability, while the two year follow-up data set resulted in $80 \%$ reliability. 


\section{Comparison of Data Sets}

The level of significance was set at .05 or $5 \%$ for all of the chi-square tests conducted. If the p-value for the tests conducted was .05 or less the researchers could be at least $95 \%$ confident that the results from the tests conducted were accurate.

\section{Summary}

This thesis is part of a longitudinal study, consisting of data collection over a five year period of time. For the purposes of this thesis only the original data collected during the summer of 2006 and the two year follow-up data collected in 2008 will be investigated and analyzed. The subjects for the initial data collection were 510 female and male participants from courses offered at Outward Bound program sites in the Rocky Mountain Mountains of Colorado and NOLS program sites in the Wind River Mountains near Lander, Wyoming. Participation in the study was voluntary and participants were selected using a convenience sampling method. Follow-up interviews were conducted with the original study participants who were selected using a convenience sampling method. The data for this study was collected using semistructured personal interviews for the initial data collection and follow-up phone interviews for the two year follow-up.

The laddering technique was the procedure used to organize and measure the means-end data collected. The LadderMap software package was used to analyze the laddering data and graphically display the connections between participant attributes, consequences, and values. The categorical statistical procedure of chi-square testing, specifically two types of hypothesis tests, a test of independence and a goodness-of-fit test, were used to see if there was a change in the number of times participants mentioned particular values two years after their wilderness 
program ended. Intercoder testing was the procedure used to check the reliability of the laddering data and the level of significance was set at $5 \%$ for the chi-square tests. 


\section{CHAPTER 4}

\section{RESULTS}

This chapter will present the results of the study including descriptive statistics from the initial and two year follow-up data collections, a means-end analysis of the two year follow-up data collection, and categorical statistical procedures used to compare the two data collections to investigate reported change in values over time.

\section{Descriptive Findings}

\section{Initial Data Collection}

A total of 510 interviews were conducted with OB and NOLS program participants in the summer of 2006. OB participants totaled $32 \%(n=162)$ of interviews conducted and NOLS participants totaled $68 \%(n=348)$ of interviews (see table 4.1$)$. Of the 510 total participants between both programs, $34 \%(n=173)$ were female, and 66\% $(n=337)$ were male (see table 4.2). Table 4.1

Participation in Initial Data Collection by Organization

\begin{tabular}{|l|c|c|}
\hline Organization & $\begin{array}{c}\text { Frequency } \\
(\mathrm{n}=510)\end{array}$ & $\begin{array}{c}\text { Percentage } \\
(100 \%)\end{array}$ \\
\hline OB & 162 & 32 \\
\hline NOLS & 348 & 68 \\
\hline
\end{tabular}

Table 4.2

Participation in Initial Data Collection by Gender

\begin{tabular}{|l|c|c|}
\hline Gender & $\begin{array}{c}\text { Frequency } \\
(\mathrm{n}=510)\end{array}$ & $\begin{array}{c}\text { Percentage } \\
(100 \%)\end{array}$ \\
\hline Male & 337 & 66 \\
\hline Female & 173 & 34 \\
\hline
\end{tabular}




\section{Two Year Follow-Up Data Collection}

A total of 197 follow-up interviews were conducted with participants in 2008. OB participants totaled $45 \%(n=89)$ of interviews conducted and NOLS participants totaled $55 \%(n=$ 108) of interviews (see table 4.3). Of the 197 participants interviewed between both programs, $35 \%(n=69)$ were female, and $65 \%(n=128)$ were male (see table 4.4$)$.

Table 4.3

Participation in Two Year Follow-Up Data Collection by Organization

\begin{tabular}{|l|c|c|}
\hline Organization & $\begin{array}{c}\text { Frequency } \\
(\mathrm{n}=197)\end{array}$ & $\begin{array}{c}\text { Percentage } \\
(100 \%)\end{array}$ \\
\hline OB & 89 & 45 \\
\hline NOLS & 108 & 55 \\
\hline
\end{tabular}

Table 4.4

Participation in Two Year Follow-Up Data Collection by Gender

\begin{tabular}{|l|c|c|}
\hline Gender & $\begin{array}{c}\text { Frequency } \\
(\mathrm{n}=197)\end{array}$ & $\begin{array}{c}\text { Percentage } \\
(100 \%)\end{array}$ \\
\hline Male & 128 & 65 \\
\hline Female & 69 & 35 \\
\hline
\end{tabular}

\section{Ethnicity of Participants from Initial Data Collection}

The participants were asked to self report their race or ethnicity and the results were as follows: $88 \%(n=450)$ were white or Caucasian, $2 \%(n=12)$ were black or African American, $2 \%(n=9)$ identified as other, 3\% $(n=16)$ were Asian or Pacific Islander, $4 \%(n=20)$ were Hispanic or Latino, and 1\% $(n=3)$ did not respond (see table 4.5). 
Table 4.5

Participation in Initial Data Collection by Ethnic/Racial Group

\begin{tabular}{|l|c|c|}
\hline Ethnic group & $\begin{array}{c}\text { Frequency } \\
(\mathrm{n}=510)\end{array}$ & $\begin{array}{c}\text { Percentage } \\
(100 \%)\end{array}$ \\
\hline White or Caucasian & 450 & 88 \\
\hline Black or African American & 12 & 2 \\
\hline American Indian/Native American & 0 & 0 \\
\hline Asian or Pacific Islander & 16 & 3 \\
\hline Hispanic or Latino & 20 & 4 \\
\hline Other & 9 & 2 \\
\hline Did not answer & 3 & 1 \\
\hline
\end{tabular}

Ethnicity of Participants from Two Year Follow-Up Data Collection

The participants were asked to self report their race or ethnicity and the results were as follows: $92 \%(n=181)$ of participants were white or Caucasian, $2 \%(n=4)$ were black or African American, 2\% $(n=4)$ identified as other, 3\% $(n=5)$ were Asian or Pacific Islander, and 2\% $(n=$ 3) were Hispanic or Latino (see table 4.6).

Table 4.6

Participation in Two Year Follow-Up Data Collection by Ethnic/Racial Group

\begin{tabular}{|l|c|c|}
\hline Ethnic group & $\begin{array}{c}\text { Frequency } \\
(\mathrm{n}=197)\end{array}$ & $\begin{array}{c}\text { Percentage } \\
(100 \%)\end{array}$ \\
\hline White or Caucasian & 181 & 92 \\
\hline Black or African American & 4 & 2 \\
\hline American Indian/Native American & 0 & 0 \\
\hline Asian or Pacific Islander & 5 & 3 \\
\hline Hispanic or Latino & 3 & 2 \\
\hline Other & 4 & 2 \\
\hline Did not answer & 0 & 0 \\
\hline
\end{tabular}




\section{Participants by Age Group from Initial Data Collection}

Participants reported their birth year and based upon their response, researchers coded their age in one of nine categories. Each age group was given a corresponding group number from 1-9. Group one $(n=102)$ consisted of ages $14-15$, group two $(n=205)$ was 16-17, group three $(n=86)$ was $18-19$, group four $(n=46)$ was $20-21$, group five $(n=36)$ was $22-25$, group six $(n=16)$ was $26-30$, group seven $(n=2)$ was $31-40$, group eight $(n=8)$ was $41-49$, and group nine $(n=5)$ was participants $50+$ (see table 4.7$)$.

Table 4.7

Participation in Initial Data Collection by Age Group

\begin{tabular}{|l|c|c|c|}
\hline Age group & Age range & $\begin{array}{c}\text { Frequency } \\
(\mathrm{n}=510)\end{array}$ & $\begin{array}{c}\text { Percentage } \\
(100 \%)\end{array}$ \\
\hline 1 & $14-15$ & 102 & 20 \\
\hline 2 & $16-17$ & 205 & 41 \\
\hline 3 & $18-19$ & 86 & 17 \\
\hline 4 & $20-21$ & 46 & 9 \\
\hline 5 & $22-25$ & 36 & 7 \\
\hline 6 & $26-30$ & 16 & 3 \\
\hline 7 & $31-40$ & 2 & .00 \\
\hline 8 & $41-49$ & 8 & .02 \\
\hline 9 & $50+$ & 5 & .1 \\
\hline Did not respond & & 4 & .07 \\
\hline
\end{tabular}




\section{Participants by Age Group from Two Year Follow-Up Data Collection}

The same coding categories for age were used in this data collection (see table 4.8).

Table 4.8

Participation in Two Year Follow-Up Data Collection by Age Group

\begin{tabular}{|l|c|c|c|}
\hline Age group & Age range & $\begin{array}{c}\text { Frequency } \\
(\mathrm{n}=197)\end{array}$ & $\begin{array}{c}\text { Percentage } \\
(100 \%)\end{array}$ \\
\hline 1 & $14-15$ & 4 & 2 \\
\hline 2 & $16-17$ & 54 & 27 \\
\hline 3 & $18-19$ & 78 & 40 \\
\hline 4 & $20-21$ & 33 & 17 \\
\hline 5 & $22-25$ & 13 & 7 \\
\hline 6 & $26-30$ & 9 & 4 \\
\hline 7 & $31-40$ & 4 & 2 \\
\hline 8 & $41-49$ & 1 & .05 \\
\hline 9 & $50+$ & 1 & .05 \\
\hline
\end{tabular}

\section{Occupation from Initial Data Collection}

When asked to self-report their occupation, $89 \%(n=453)$ of participants reported being a student, $10 \%(n=53)$ had an occupation other than student, and $0.8 \%(n=4)$ did not respond (see table 4.9).

Table 4.9

Participation in Initial Data Collection by Occupation

\begin{tabular}{|l|c|c|}
\hline Occupation & $\begin{array}{c}\text { Frequency } \\
(\mathrm{n}=510)\end{array}$ & $\begin{array}{c}\text { Percentage } \\
(100 \%)\end{array}$ \\
\hline Student & 453 & 89 \\
\hline Other & 53 & 10 \\
\hline Did not respond & 4 & 1 \\
\hline
\end{tabular}




\section{Occupation from Two Year Follow-Up Data Collection}

When asked to self-report their occupation, $86 \%(n=169)$ of participants reported being a student and 14\% (n=28) had an occupation other than student (see table 4.10).

Table 4.10

Participation in Two Year Follow-Up Data Collection by Occupation

\begin{tabular}{|l|c|c|}
\hline Occupation & $\begin{array}{c}\text { Frequency } \\
(\mathrm{n}=197)\end{array}$ & $\begin{array}{c}\text { Percentage } \\
(100 \%)\end{array}$ \\
\hline Student & 169 & 86 \\
\hline Other & 28 & 14 \\
\hline Did not respond & 0 & 0 \\
\hline
\end{tabular}

\section{Previous Attendance from Initial Data Collection}

Participants were asked if they had previously attended a course with the same program in the past and $91 \%(n=465)$ said they had not previously attended a course, while $9 \%(n=41)$ stated they had previously attended a course (see table 4.11).

Table 4.11

Previous Attendance for Participants of Initial Data Collection

\begin{tabular}{|l|c|c|}
\hline Previous Attendance & $\begin{array}{c}\text { Frequency } \\
(\mathrm{n}=510)\end{array}$ & $\begin{array}{c}\text { Percentage } \\
(100 \%)\end{array}$ \\
\hline Yes & 43 & 8 \\
\hline No & 467 & 92 \\
\hline
\end{tabular}




\section{Previous Attendance from Two Year Follow-Up Data Collection}

Participants were asked if they had previously attended a course with the same program in the past and $90 \%(n=178)$ stated they had not previously attended a course, while $10 \%$ ( $n=$ 19) stated they had previously attended a course (see table 4.12).

Table 4.12

Previous Attendance for Participants of Two Year Follow-Up Data Collection

\begin{tabular}{|l|c|c|}
\hline Previous Attendance & $\begin{array}{c}\text { Frequency } \\
(\mathrm{n}=197)\end{array}$ & $\begin{array}{c}\text { Percentage } \\
(100 \%)\end{array}$ \\
\hline Yes & 19 & 10 \\
\hline No & 178 & 90 \\
\hline
\end{tabular}

Course Length from Initial Data Collection

The length of the course ranged from 14-20 days, which 51\% of participants $(n=260)$ attended, $42 \%(n=213)$ had courses of $21-27$ days, $6 \%(n=32)$ had courses of 28 or more days, and $1 \%(n=5)$ did not respond (see table 4.13).

Table 4.13

Course Length for Participants of Initial Data Collection

\begin{tabular}{|l|c|c|}
\hline Course Length & $\begin{array}{c}\text { Frequency } \\
(\mathrm{n}=510)\end{array}$ & $\begin{array}{c}\text { Percentage } \\
(100 \%)\end{array}$ \\
\hline 1 (14-20 days) & 260 & 51 \\
\hline $2(21-27$ days $)$ & 213 & 42 \\
\hline 3 (28 or more days $)$ & 32 & 6 \\
\hline Did not respond & 5 & 1 \\
\hline
\end{tabular}




\section{Course Length from Two Year Follow-Up Data Collection}

Course length ranged from 14-20 days, which $45 \%$ of participants $(n=88)$ attended, $47 \%$ $(n=93)$ had courses of 21-27 days, and 8\% ( $n=16)$ had courses of 28 or more days (see table 4.14).

Table 4.14

Course Length for Participants of Two Year Follow-Up Data Collection

\begin{tabular}{|l|c|c|}
\hline Course Length & $\begin{array}{c}\text { Frequency } \\
(\mathrm{n}=197)\end{array}$ & $\begin{array}{c}\text { Percentage } \\
(100 \%)\end{array}$ \\
\hline 1 (14-20 days) & 88 & 45 \\
\hline $2(21-27$ days $)$ & 93 & 47 \\
\hline 3 (28 or more days) & 16 & 8 \\
\hline Did not respond & 0 & 0 \\
\hline
\end{tabular}

\section{Recommending OB/NOLS to a Friend from Initial Data Collection}

Participants were asked if they would recommend a course with their respective programs to a friend and $99 \%(n=505)$ said yes, $0.2 \%(n=1)$ said no, and $0.8 \%(n=4)$ did not respond (see table 4.15).

Table 4.15

Likelihood of Participants Recommending an OB/NOLS Course to a Friend from Initial Data Collection

\begin{tabular}{|l|c|c|}
\hline Recommend Course & $\begin{array}{c}\text { Frequency } \\
(\mathrm{n}=510)\end{array}$ & $\begin{array}{c}\text { Percentage } \\
(100 \%)\end{array}$ \\
\hline Yes & 505 & 99 \\
\hline No & 1 & 0.2 \\
\hline Did not respond & 4 & 0.8 \\
\hline
\end{tabular}


Recommending OB/NOLS to a Friend from Two Year Follow-Up Data Collection

Participants were asked if they would recommend a course with their respective programs to a friend and $98 \%(n=192)$ said yes while $2 \%(n=4)$ said no (see table 4.16$)$.

Table 4.16

Likelihood of Participant Recommending an OB/NOLS Course to a Friend from Two Year Follow-Up Data Collection

\begin{tabular}{|l|c|c|}
\hline Recommend Course & $\begin{array}{c}\text { Frequency } \\
(\mathrm{n}=197)\end{array}$ & $\begin{array}{c}\text { Percentage } \\
(100 \%)\end{array}$ \\
\hline Yes & 193 & 98 \\
\hline No & 4 & 2 \\
\hline Did not respond & 0 & 0 \\
\hline
\end{tabular}

Outward Bound Course Demographics

Outward Bound courses used in this study were based in one of three base camps;

Marble, CO, Leadville, CO, and Silverton, CO. Course lengths varied from 14 days to 22 days. All courses were open to the public and many had scholarship funded participants.

Gender of $O B$ Participants from Initial Data Collection

A total of 162 participants were interviewed, 63\% $(n=102)$ were male and $37 \%(n=60)$ were female (see table 4.17).

Table 4.17

OB Participants from Initial Data Collection by Gender

\begin{tabular}{|l|c|c|}
\hline Gender & $\begin{array}{c}\text { Frequency } \\
(\mathrm{n}=162)\end{array}$ & $\begin{array}{c}\text { Percentage } \\
(100 \%)\end{array}$ \\
\hline Males & 102 & 63 \\
\hline Females & 60 & 37 \\
\hline
\end{tabular}


Gender of OB Participants from Two Year Follow-Up Data Collection

A total of 89 participants were interviewed, $58 \%(n=52)$ were male and $42 \%(n=37)$

were female (see table 4.18).

Table 4.18

OB Participants from Two Year Follow-Up Data Collection by Gender

\begin{tabular}{|l|c|c|}
\hline Gender & $\begin{array}{c}\text { Frequency } \\
(\mathrm{n}=89)\end{array}$ & $\begin{array}{c}\text { Percentage } \\
(100 \%)\end{array}$ \\
\hline Males & 52 & 58 \\
\hline Females & 37 & 42 \\
\hline
\end{tabular}

\section{NOLS Course Demographics}

All NOLS courses used in this study were based in Lander, Wyoming and varied in length from 14 days to 6 months. Of the 40 total courses included, 37 were open to the public and 3 were privately contracted with the US Naval Academy.

\section{NOLS Participants by Gender from Initial Data Collection}

A total of 348 participants were interviewed, 67\% $(n=235)$ were male and $33 \%(n=113)$ were female (see table 4.19).

Table 4.19

NOLS Participants from Initial Data Collection by Gender

\begin{tabular}{|l|c|c|}
\hline Gender & $\begin{array}{c}\text { Frequency } \\
(\mathrm{n}=348)\end{array}$ & $\begin{array}{c}\text { Percentage } \\
(100 \%)\end{array}$ \\
\hline Males & 235 & 67 \\
\hline Females & 113 & 33 \\
\hline
\end{tabular}


NOLS Participants by Gender from Two Year Follow-Up Data Collection

A total of 108 participants were interviewed, $70 \%(n=76)$ were male and $30 \%(n=32)$ were female (see table 4.20).

Table 4.20

NOLS Participants from Two Year Follow-Up Data Collection by Gender

\begin{tabular}{|l|c|c|}
\hline Gender & $\begin{array}{c}\text { Frequency } \\
(\mathrm{n}=108)\end{array}$ & $\begin{array}{c}\text { Percentage } \\
(100 \%)\end{array}$ \\
\hline Males & 76 & 70 \\
\hline Females & 32 & 30 \\
\hline
\end{tabular}

\section{Means-End Analysis}

The first objective of this study was to gain a better understanding of the attributes, consequences, and personal values that individuals retained from participation in a wilderness adventure program. Hierarchical value maps (HVM) were created from the data to show the associations between the attributes, consequences, and values. Instead of treating the three elements independent of each other, means-end theory considers them fundamentally interrelated. The linkages between the attributes, consequences, and values are described as means-end chains (Gutman, 1982). Gutman goes on to state that each link in the means-end chain describes how a participant's thoughts progress from either attribute to consequence or consequence to value so the thought process is clearly followed from start to finish.

The means-end analysis began when a list of attributes, consequences, and values was created based on phrases and key words that emerged from the interviews (see appendix $\mathrm{C}$ for the outcomes list). The content codes created were then tested in a blind review by an independent coder to determine intercoder reliability. The original data set was tested by an 
independent coder and resulted in $87 \%$ reliability, while the two year follow-up data set resulted in $80 \%$ reliability.

When creating a HVM, a specific cutoff value was chosen. The cutoff value refers to the number of times concepts were associated together in the implication matrix. The implication matrix summarizes the number of times each concept is associated with each of the other concepts in the respondents' ladders, determining the dominant connections between the key attributes, consequences, and values. The lower the cutoff value the higher percentage of associations between the concepts will be displayed by the HVM. Gengler and Reynolds (1995) stated that the cutoff value needs to strike a balance between the aesthetic quality of the HVM and the quantitative validity of the data being presented. In other words, the HVM needs enough of the associations between the concepts displayed to represent the majority of the means-end data collected but not have so much data that the HVM is rendered incomprehensible.

In the graphical display of the HVM the attributes are positioned at the bottom of the map and illustrated as white circles. The consequences are positioned in the middle of the map and represented by gray circles. The value concepts are positioned at the top of the map and represented by black circles. The size of a given circle is proportional to the number of times a particular concept was mentioned by participants. Therefore, the bigger the circle the more participants mentioned that particular concept. The thickness of the lines on the HVM that link the concepts together are proportional to the number of sample participants mention that particular link in the laddering process. Therefore, the thicker the line the more participants linked those concepts together. 


\section{HVM for All Participants}

Figure 4.1 illustrates the associations generated from all of the individuals who participated in the two year follow-up data collection for this study $(N=197)$. A cutoff value of 4 (87\% of associations between the concepts) was used to create this HVM. The most frequently mentioned attributes included the following: group $(n=116)$, expeditioning $(n=82)$, overall course $(n=57)$, wilderness $(n=49)$, climbing $(n=43)$, and instruction $(n=41)$. The most frequently mentioned consequences included the following: interactions $(n=145)$, being challenged ( $n=101)$, personal growth $(n=92)$, fun/excitement $(n=85)$, new experience $(n=$ $81)$, and new perspective $(n=78)$. The most frequently mentioned values included the following: transference $(n=139)$, self-respect/esteem/confidence $(n=126)$, sense of accomplishment $(n=$ 97), and warm relationships with others $(n=96)$.

The majority of the attributes in this HVM were associated with participants being challenged, including strong associations with the attributes of group, expeditioning, overall course, climbing, and wilderness. Being challenged led to a strong association with interactions, including relying and accepting support from the group and using teamwork to accomplish tasks. Interactions led to learning about, observing or displaying leadership, which then led to development of hard skills, such as cooking, tying knots, orienteering, and belaying. Developing hard skills led to participants enjoying the experience, gaining a new perspective, feeling a sense of independence, and feeling motivated and inspired.

After gaining a new perspective many participants felt a greater appreciation of the natural environment, this in turn allowed participants to reflect on their own growth or maturity during the course. From this point feelings of independence, perseverance, reflection, and to a lesser extent resourcefulness led to a sense of personal growth for the majority of participants. 
This sense of growth led the majority of participants to feel a sense of accomplishment, which then motivated them to transfer course benefits and outcomes to their lives. Transference occurred for some participants in greater self-fulfillment, while a larger proportion acknowledged warm relationships with others, greater self-awareness, higher selfrespect/esteem/confidence, and more fun and enjoyment of life. 


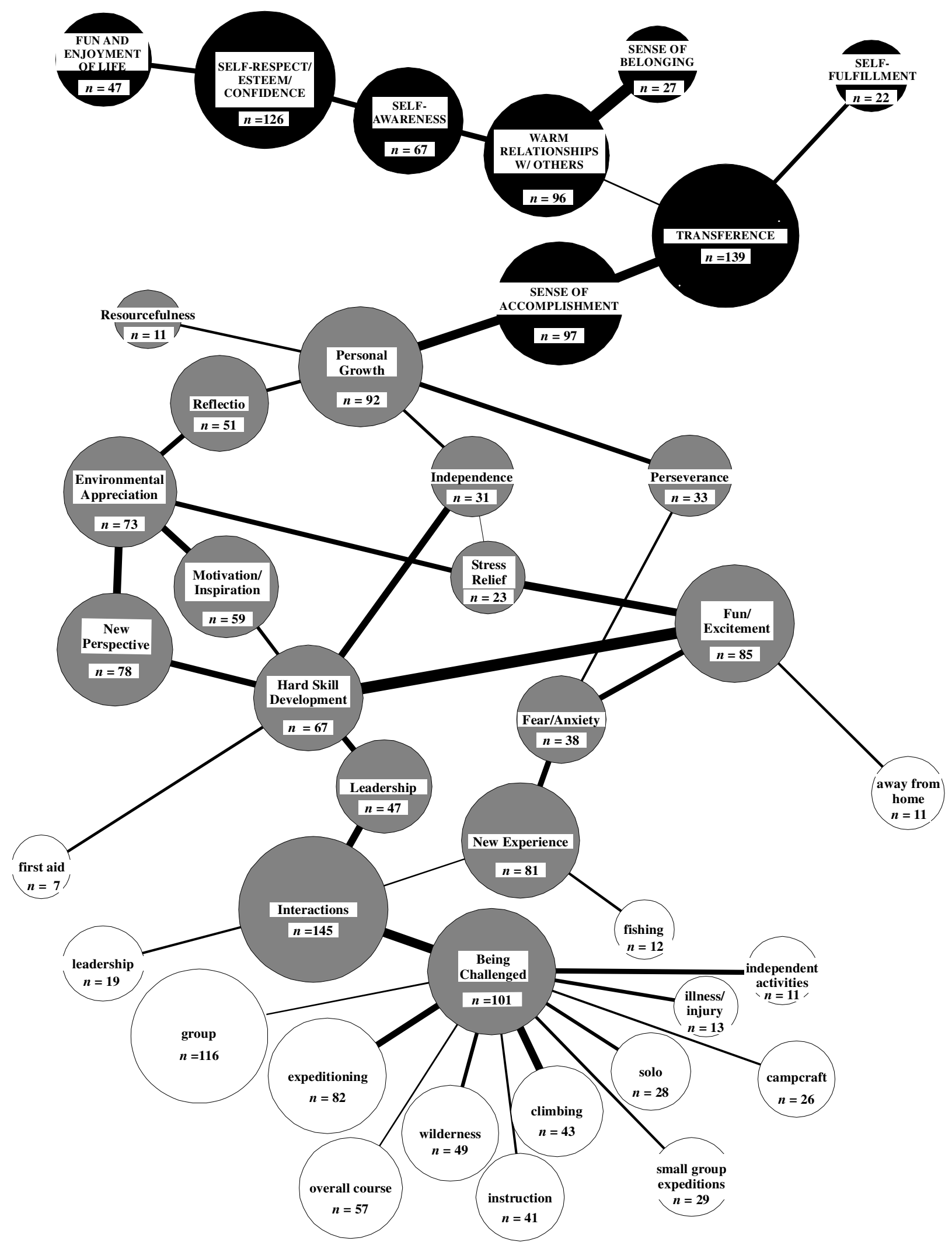

Figure 4.1. Hierarchical Value Map for All Participants $(N=197)$ 


\section{Outward Bound Participants HVM}

Figure 4.2 illustrates the associations generated from all of the individuals who were sampled from the Outward Bound courses $(N=89)$. A cutoff value of $2(94 \%$ of associations between the concepts) was used to create this HVM. The most frequently mentioned attributes included the following: group $(n=57)$, expeditioning $(n=43)$, solo $(n=27)$, overall course $(n=$ $25)$, climbing $(n=21)$, and wilderness $(n=20)$. The most frequently mentioned consequences included the following: interactions $(n=68)$, being challenged $(n=50)$, new perspective $(n=$ $38)$, personal growth $(n=36)$, new experience $(n=34)$, and fun/excitement $(n=32)$. The most frequently mentioned values included the following: transference $(n=53)$, selfrespect/esteem/confidence $(n=51)$, sense of accomplishment $(n=44)$, warm relationships with others $(n=44)$, and self-awareness $(n=35)$.

The majority of the attributes in this HVM were associated with the consequence of being challenged, including strong associations with the attributes of group, expeditioning, wilderness, overall course, solo, and climbing. The attributes of small group expeditions, leadership activities, and away from home were all directly associated with the consequence of interactions, though these attributes were mentioned by a small proportion of participants. Being challenged did not have much of a connection to group interactions, with only a weak association with the consequence of stress relief to connect them, which only a few participants mentioned. The majority of OB participants mentioned group interactions, which led participants to feel motivated and inspired, as well as exposed them to a new experience.

The new experience led some participants to feel scared and anxious, which helped some feel a sense of perseverance while others excitement and fun. A reflection of one's growth or maturity during the experience, a sense of perseverance, and exposure and experience in 
leadership roles led some participants to gain a new perspective. This new perspective as well as hard skill development helped some participants to feel a sense of independence, which in turn led to a greater appreciation of the natural environment. Greater appreciation of the environment allowed some participants to feel a sense of personal growth, who then felt a sense of accomplishment.

A sense of accomplishment helped many participants to feel motivated to transfer course benefits and outcomes into their lives. Aspects of participants' lives affected by this transference of course outcomes included greater self-respect/esteem/confidence for many participants; some experienced more fun and enjoyment of life due to this greater self-respect/esteem/confidence and a greater number experienced warm relationships with others. Warm relationships with others led to a sense of belonging and greater self-awareness. 


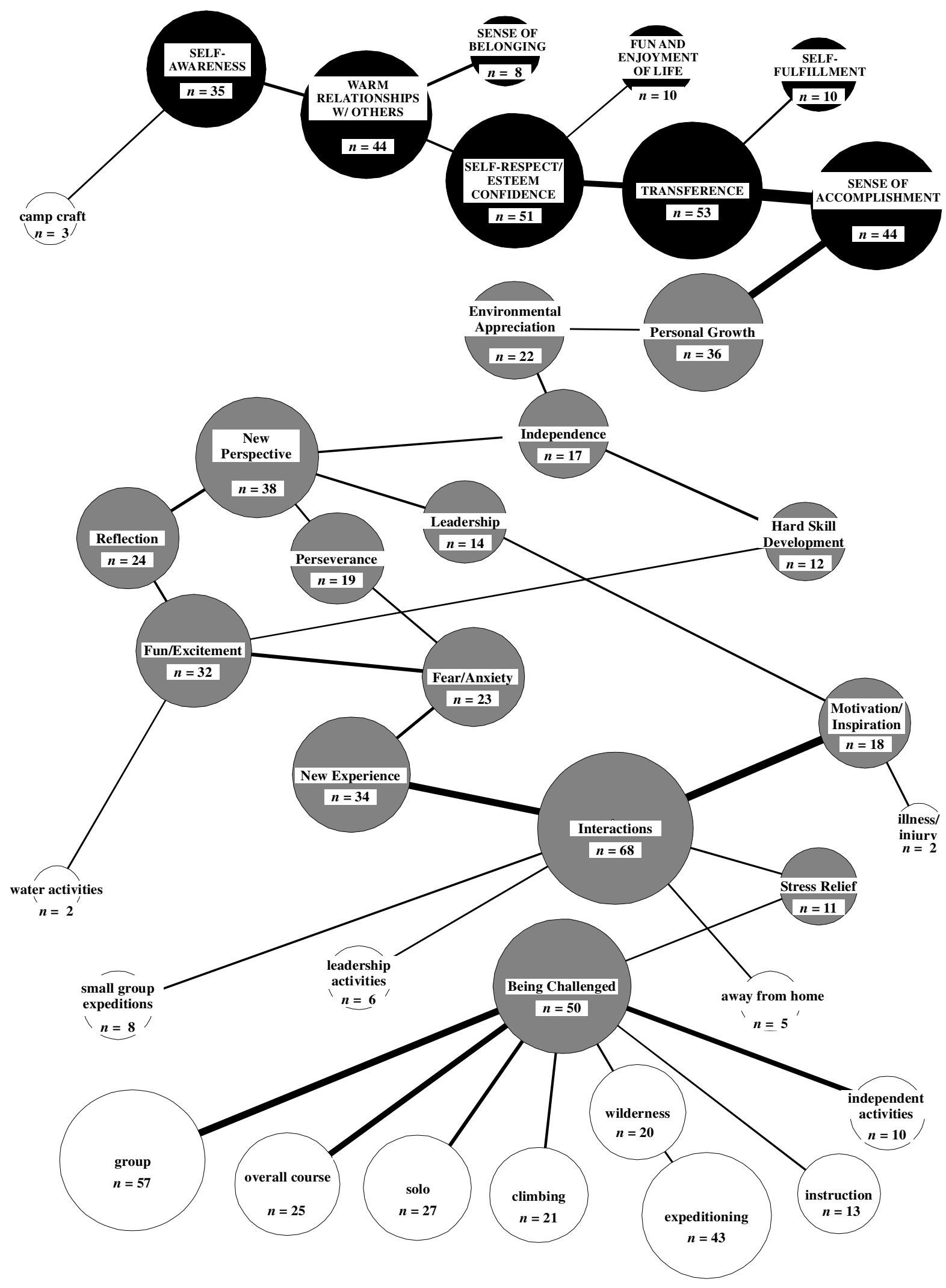

Figure 4.2. Hierarchical Value Map for Outward Bound Participants $(N=89)$ 


\section{NOLS Participants HVM}

Figure 4.3 illustrates the associations generated from all of the participants from the NOLS courses $(N=108)$. A cutoff value of $2(97 \%$ of associations between the concepts) was used to create this HVM. The most frequently mentioned attributes included the following: group ( $n=58)$, expeditioning $(n=38)$, overall course $(n=31)$, wilderness $(n=29)$, and instruction $(n=$ 26). The most frequently mentioned consequences included the following: interactions $(n=75)$, personal growth $(n=55)$, hard skill development $(n=55)$, fun/excitement $(n=52)$, being challenged $(n=50)$, and environmental appreciation $(n=50)$. The most frequently mentioned values included the following: transference $(n=84)$, self-respect/esteem/confidence $(n=73)$, sense of accomplishment $(n=52)$, warm relationships with others $(n=51)$, and fun and enjoyment of life $(n=37)$.

The majority of the attributes in this HVM were associated with the consequence of interactions, including group, expeditioning, overall course, and instruction. The attributes of wilderness and climbing had strong associations with the consequence of new experience. The majority of NOLS participants mentioned interactions with the group, which was a new experience for about half of these participants. This new experience caused feelings of fun and excitement in many participants and fear and anxiety in a smaller amount. Fun and excitement, as well as fear and anxiety caused about half of the NOLS participants to feel challenged, which they associated with leadership, independence, perseverance, and resourcefulness.

Learning about, observing, or displaying leadership, feeling a sense of independence, as well as perseverance led many participants to develop hard skills. Hard skill development then motivated and inspired some participants, as well as provided a new perspective.

Motivated/inspired participants who gained a new perspective then felt a greater appreciation for 
the natural environment. Only a small number of participants made a connection between this greater environmental appreciation and stress relief. Those few that did connected that stress relief to a reflection of one's growth or maturity on the course, which then helped participants to feel a sense of personal growth.

A sense of personal growth led many NOLS participants to feel a sense of accomplishment, which then motivated them to transfer the benefits and outcomes gained from their course into their lives. Many participants mentioned transference occurring in warm relationships with others, which helped some participants to gain a greater sense of belonging and greater self-awareness. Greater self-awareness led the majority of participants to gain more self-respect/esteem/confidence, which helped some to experience more fun and enjoyment of life. A small number of participants experienced greater self-fulfillment as a result of more fun and enjoyment of life. 


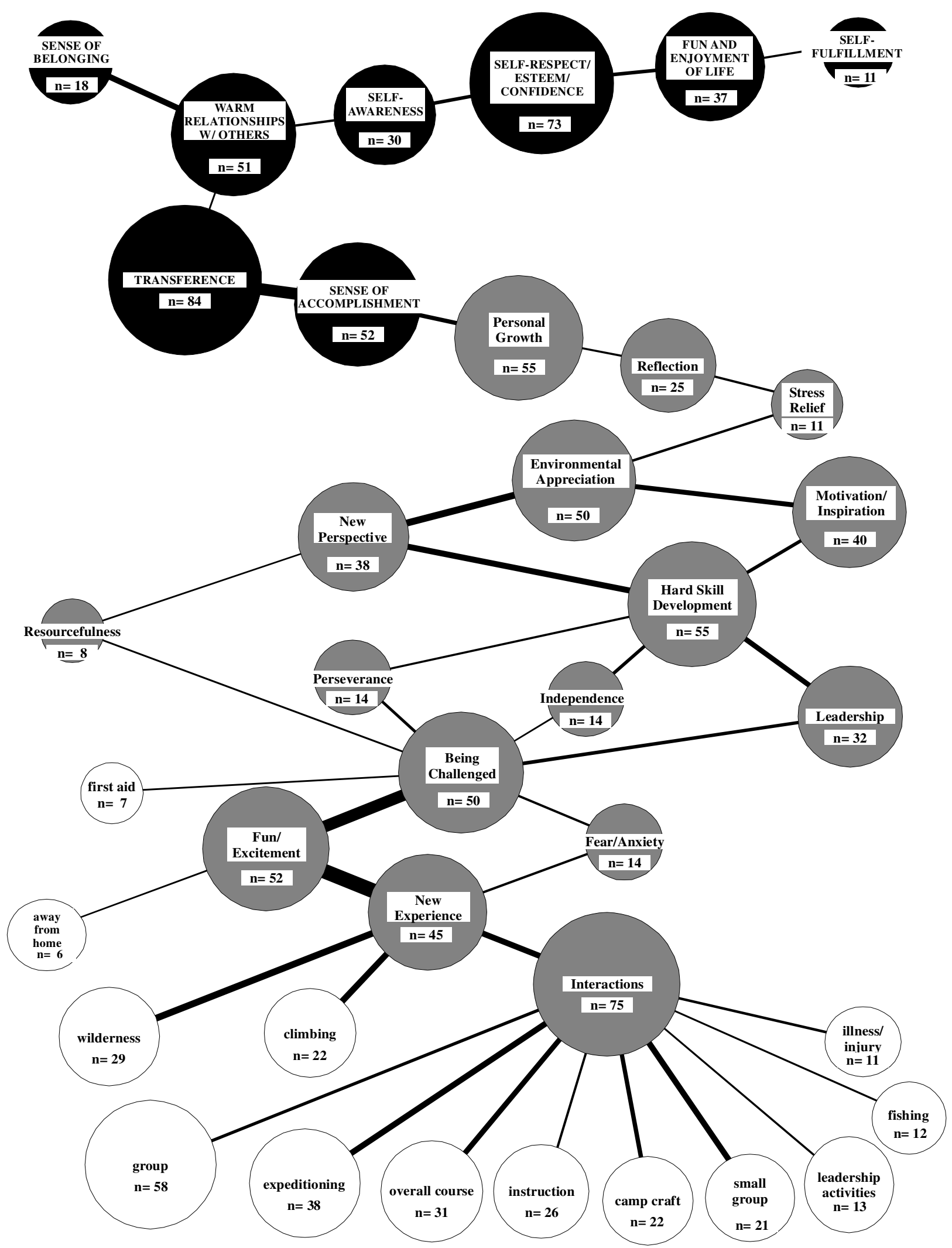

Figure 4.3. Hierarchical Value Map of NOLS Participants $(N=108)$ 


\section{Comparison of Data Sets}

A comparison between the two data collections was done to investigate reported change in values over time. Categorical variables were created for the type of program sampled and for the change in the number of times sample participants mentioned particular values from the original to the second year follow-up data collection periods. For the variable of change in value over time, three categories were created: 1) if a participant mentioned a value fewer times in the second year follow-up data collection then it was categorized as a negative change; 2) if a value was mentioned the same amount of times between the two data collections then it was categorized as no change; and 3) if a value was mentioned more times in the second year followup data collection then it was categorized as a positive change. See appendix $\mathrm{C}$ for a complete list of the values tested.

A Pearson's chi-square test of independence was conducted to cross tabulate the program type with each change in a particular value. Because there were eight values, eight tests were run, and the hypotheses for each test were as follows:

$H_{o}$ : No relationship exists between program type and change in value.

$H_{1}$ : A relationship does exist between program type and change in value.

The level of significance for all tests was 0.05 or $5 \%$.

For the chi-square test of independence for all eight of the values, the p-value was only considered significant for the values of fun and enjoyment of life $(\mathrm{p}$-value $=0.005)$ and transference ( $\mathrm{p}$-value $=0.002)$. So for these tests the null hypothesis was rejected and we were 95\% confident that a relationship did exist between program type and change in the values of fun and enjoyment of life and transference. It should be noted that for the value of sense of belonging the frequencies for the negative change category for both NOLS and OB were fewer than five, 
which breaks a technical condition of this type of chi-square test that all expected cell counts should be at least five. The unmet technical condition was noted but not deemed significant due to the small proportion of this change category to the overall sample size. See tables 4.21 through 4.28 for complete results of the tests of independence.

Table 4.21

Chi-Square Test of Independence for the Value Fun and Enjoyment of Life

\begin{tabular}{|l|c|c|c|c|c|c|}
\hline Change in Value & \multicolumn{2}{|c|}{ Negative } & \multicolumn{2}{c|}{ No Change } & \multicolumn{2}{c|}{ Positive } \\
\hline & $\begin{array}{c}\text { Frequency } \\
(n)\end{array}$ & $\begin{array}{c}\text { Percentage } \\
(100 \%)\end{array}$ & $\begin{array}{c}\text { Frequency } \\
(n)\end{array}$ & $\begin{array}{c}\text { Percentage } \\
(100 \%)\end{array}$ & $\begin{array}{c}\text { Frequency } \\
(n)\end{array}$ & $\begin{array}{c}\text { Percentage } \\
(100 \%)\end{array}$ \\
\hline NOLS & 14 & 13 & 63 & 59 & 30 & 28 \\
\hline OB & 10 & 11 & 70 & 79 & 9 & 10 \\
\hline ALL & 24 & 12 & 133 & 68 & 39 & 20 \\
\hline \multicolumn{7}{|c|}{ Statistically significant P-value at the .05 level } \\
\hline
\end{tabular}

Table 4.22

Chi-Square Test of Independence for the Value Self-Awareness

\begin{tabular}{|l|c|c|c|c|c|c|}
\hline Change in Value & \multicolumn{2}{|c|}{ Negative } & \multicolumn{2}{c|}{ No Change } & \multicolumn{2}{c|}{ Positive } \\
\hline & $\begin{array}{c}\text { Frequency } \\
(n)\end{array}$ & $\begin{array}{c}\text { Percentage } \\
(100 \%)\end{array}$ & $\begin{array}{c}\text { Frequency } \\
(n)\end{array}$ & $\begin{array}{c}\text { Percentage } \\
(100 \%)\end{array}$ & $\begin{array}{c}\text { Frequency } \\
(n)\end{array}$ & $\begin{array}{c}\text { Percentage } \\
(100 \%)\end{array}$ \\
\hline NOLS & 18 & 17 & 67 & 63 & 22 & 20 \\
\hline OB & 18 & 20 & 45 & 51 & 26 & 29 \\
\hline ALL & 36 & 18 & 112 & 57 & 48 & 25 \\
\hline \multicolumn{6}{|c|}{ N= 196} & Degrees of Freedom =2 P-Value $=0.220$ \\
\hline
\end{tabular}


Table 4.23

Chi-Square Test of Independence for the Value Self-Fulfillment

\begin{tabular}{|l|c|c|c|c|c|c|}
\hline Change in Value & \multicolumn{2}{|c|}{ Negative } & \multicolumn{2}{c|}{ No Change } & \multicolumn{2}{c|}{ Positive } \\
\hline & $\begin{array}{c}\text { Frequency } \\
(n)\end{array}$ & $\begin{array}{c}\text { Percentage } \\
(100 \%)\end{array}$ & $\begin{array}{c}\text { Frequency } \\
(n)\end{array}$ & $\begin{array}{c}\text { Percentage } \\
(100 \%)\end{array}$ & $\begin{array}{c}\text { Frequency } \\
(n)\end{array}$ & $\begin{array}{c}\text { Percentage } \\
(100 \%)\end{array}$ \\
\hline NOLS & 6 & 6 & 90 & 84 & 11 & 10 \\
\hline OB & 13 & 15 & 68 & 76 & 8 & 9 \\
\hline ALL & 19 & 10 & 158 & 81 & 19 & 9 \\
\hline \multicolumn{7}{|c|}{ N $=196$} \\
\hline
\end{tabular}

Table 4.24

Chi-Square Test of Independence for the Value Self-Respect/Esteem/Confidence

\begin{tabular}{|l|c|c|c|c|c|c|}
\hline Change in Value & \multicolumn{2}{|c|}{ Negative } & \multicolumn{2}{c|}{ No Change } & \multicolumn{2}{c|}{ Positive } \\
\hline & $\begin{array}{c}\text { Frequency } \\
(n)\end{array}$ & $\begin{array}{c}\text { Percentage } \\
(100 \%)\end{array}$ & $\begin{array}{c}\text { Frequency } \\
(n)\end{array}$ & $\begin{array}{c}\text { Percentage } \\
(100 \%)\end{array}$ & $\begin{array}{c}\text { Frequency } \\
(n)\end{array}$ & $\begin{array}{c}\text { Percentage } \\
(100 \%)\end{array}$ \\
\hline OB & 18 & 20 & 38 & 43 & 33 & 37 \\
\hline NOLS & 14 & 13 & 37 & 35 & 56 & 52 \\
\hline ALL & 32 & 16 & 75 & 38 & 89 & 46 \\
\hline \multicolumn{6}{|c|}{ Statistically significant P-value at the .05 level } \\
\hline
\end{tabular}

Table 4.25

Chi-Square Test of Independence for the Value Sense of Accomplishment

\begin{tabular}{|l|c|c|c|c|c|c|}
\hline Change in Value & \multicolumn{2}{|c|}{ Negative } & No Change & \multicolumn{2}{c|}{ Positive } \\
\hline & $\begin{array}{c}\text { Frequency } \\
(n)\end{array}$ & $\begin{array}{c}\text { Percentage } \\
(100 \%)\end{array}$ & $\begin{array}{c}\text { Frequency } \\
(n)\end{array}$ & $\begin{array}{c}\text { Percentage } \\
(100 \%)\end{array}$ & $\begin{array}{c}\text { Frequency } \\
(n)\end{array}$ & $\begin{array}{c}\text { Percentage } \\
(100 \%)\end{array}$ \\
\hline NOLS & 26 & 24 & 51 & 48 & 30 & 28 \\
\hline OB & 29 & 33 & 39 & 44 & 21 & 23 \\
\hline ALL & 55 & 28 & 90 & 46 & 51 & 26 \\
\hline \multicolumn{7}{|c|}{ Statistically significant P-value at the .05 level } \\
\hline
\end{tabular}


Table 4.26

Chi-Square Test of Independence for the Value Sense of Belonging

\begin{tabular}{|c|c|c|c|c|c|c|}
\hline Change in Value & \multicolumn{2}{|c|}{ Negative } & \multicolumn{2}{|c|}{ No Change } & \multicolumn{2}{|c|}{ Positive } \\
\hline & $\begin{array}{c}\text { Frequency } \\
(n)\end{array}$ & $\begin{array}{c}\text { Percentage } \\
(100 \%)\end{array}$ & $\begin{array}{c}\text { Frequency } \\
(n)\end{array}$ & $\begin{array}{l}\text { Percentage } \\
(100 \%)\end{array}$ & $\begin{array}{c}\text { Frequency } \\
(n)\end{array}$ & $\begin{array}{c}\text { Percentage } \\
(100 \%)\end{array}$ \\
\hline NOLS & $3 *$ & 3 & 86 & 80 & 18 & 17 \\
\hline $\mathrm{OB}$ & $2^{*}$ & 2 & 79 & 89 & 8 & 9 \\
\hline ALL & 5 & 3 & 65 & 84 & 26 & 13 \\
\hline & $\mathrm{N}=196$ & Degrees of 1 & edom $=2$ & $\mathrm{P}-$ Value $=$ & .258 & \\
\hline
\end{tabular}

* Unmet Chi-square technical condition that all cell counts should be at least 5

Table 4.27

Chi-Square Test of Independence for the Value Transference

\begin{tabular}{|l|c|c|c|c|c|c|}
\hline Change in Value & \multicolumn{2}{|c|}{ Negative } & \multicolumn{2}{c|}{ No Change } & \multicolumn{2}{c|}{ Positive } \\
\hline & $\begin{array}{c}\text { Frequency } \\
(n)\end{array}$ & $\begin{array}{c}\text { Percentage } \\
(100 \%)\end{array}$ & $\begin{array}{c}\text { Frequency } \\
(n)\end{array}$ & $\begin{array}{c}\text { Percentage } \\
(100 \%)\end{array}$ & $\begin{array}{c}\text { Frequency } \\
(n)\end{array}$ & $\begin{array}{c}\text { Percentage } \\
(100 \%)\end{array}$ \\
\hline NOLS & 18 & 17 & 30 & 28 & 59 & 55 \\
\hline OB & 28 & 32 & 34 & 38 & 27 & 30 \\
\hline ALL & 46 & 23 & 64 & 33 & 86 & 44 \\
\hline \multicolumn{7}{|c|}{ Statistically significant P-value at the .05 level } \\
\hline
\end{tabular}

Table 4.28

Chi-Square Test of Independence for the Value Warm Relationships with Others

\begin{tabular}{|l|c|c|c|c|c|c|}
\hline Change in Value & \multicolumn{2}{|c|}{ Negative } & \multicolumn{2}{c|}{ No Change } & \multicolumn{2}{c|}{ Positive } \\
\hline & $\begin{array}{c}\text { Frequency } \\
(n)\end{array}$ & $\begin{array}{c}\text { Percentage } \\
(100 \%)\end{array}$ & $\begin{array}{c}\text { Frequency } \\
(n)\end{array}$ & $\begin{array}{c}\text { Percentage } \\
(100 \%)\end{array}$ & $\begin{array}{c}\text { Frequency } \\
(n)\end{array}$ & $\begin{array}{c}\text { Percentage } \\
(100 \%)\end{array}$ \\
\hline NOLS & 15 & 14 & 52 & 49 & 40 & 37 \\
\hline OB & 10 & 11 & 45 & 51 & 34 & 38 \\
\hline ALL & 25 & 13 & 97 & 49 & 74 & 38 \\
\hline \multicolumn{7}{|c|}{ S Statistically significant P-value at the .05 level } \\
\hline
\end{tabular}


As a follow-up procedure a chi-square goodness-of-fit test was conducted for all eight values to test a hypothesis about how the data was distributed across the three categories of change. The hypotheses for the goodness-of-fit tests were as follows:

$H_{o}$ : Participants were equally likely to report a negative, positive, and no change in values tested. $H_{1}$ : Participants were not equally likely to report a negative, positive, and no change in values tested.

The level of significance for all tests was 0.05 or $5 \%$.

The goodness-of-fit tests revealed significant p-values for all of the values. Therefore for all of the values the null hypothesis was rejected and we were $95 \%$ confident that participants were not equally likely to report a negative, positive, and no change. Transference and selfrespect/esteem/confidence were the only values where a higher percentage of participants showed a positive change over time. In all of the other values the highest percentage of participants revealed no change. See tables 4.29 through 4.36 for complete results of the goodness-of-fit tests.

Table 4.29

Goodness-of-Fit Test for the Value Fun and Enjoyment of Life

\begin{tabular}{|l|c|c|}
\hline Change in Value & \multicolumn{1}{|c|}{$\begin{array}{c}\text { Frequency } \\
(n=196)\end{array}$} & $\begin{array}{c}\text { Percentage } \\
(100 \%)\end{array}$ \\
\hline Negative & 24 & 12 \\
\hline No Change & 133 & 68 \\
\hline Positive & 39 & 20 \\
\hline \multicolumn{2}{|c|}{ Degrees of Freedom =2 P-Value $=0.000$} \\
\hline \multicolumn{2}{|c|}{ Statistically significant P-value at the .05 level } \\
\hline
\end{tabular}


Table 4.30

Goodness-of-Fit Test for the Value Self-Awareness

\begin{tabular}{|l|c|c|}
\hline Change in Value & \multicolumn{1}{|c|}{$\begin{array}{c}\text { Frequency } \\
(n=196)\end{array}$} & $\begin{array}{c}\text { Percentage } \\
(100 \%)\end{array}$ \\
\hline Negative & 36 & 18 \\
\hline No Change & 112 & 57 \\
\hline Positive & 48 & 25 \\
\hline \multicolumn{2}{|c|}{ Degrees of Freedom =2 P-Value $=0.000$} \\
\hline \multicolumn{2}{|c|}{ Statistically significant P-value at the .05 level } \\
\hline
\end{tabular}

Table 4.31

Goodness-of-Fit Test for the Value Self-Fulfillment

\begin{tabular}{|l|c|c|}
\hline Change in Value & $\begin{array}{c}\text { Frequency } \\
(n=196)\end{array}$ & $\begin{array}{c}\text { Percentage } \\
(100 \%)\end{array}$ \\
\hline Negative & 19 & 10 \\
\hline No Change & 158 & 81 \\
\hline Positive & 19 & 9 \\
\hline \multicolumn{2}{|c|}{ Degrees of Freedom $=2 \quad$ P-Value $=0.000$} \\
\hline \multicolumn{2}{|c|}{ Statistically significant P-value at the .05 level } \\
\hline
\end{tabular}

Table 4.32

Goodness-of-Fit Test for the Value Self-Respect/Esteem/Confidence

\begin{tabular}{|l|c|c|}
\hline Change in Value & $\begin{array}{c}\text { Frequency } \\
(n=196)\end{array}$ & $\begin{array}{c}\text { Percentage } \\
(100 \%)\end{array}$ \\
\hline Negative & 32 & 16 \\
\hline No Change & 75 & 38 \\
\hline Positive & 89 & 46 \\
\hline \multicolumn{2}{|c|}{ Degrees of Freedom =2 P-Value $=0.000$} \\
\hline \multicolumn{2}{|c|}{ Statistically significant P-value at the .05 level } \\
\hline
\end{tabular}


Table 4.33

Goodness-of-Fit Test for the Value Sense of Accomplishment

\begin{tabular}{|l|c|c|}
\hline Change in Value & $\begin{array}{c}\text { Frequency } \\
(n=196)\end{array}$ & $\begin{array}{c}\text { Percentage } \\
(100 \%)\end{array}$ \\
\hline Negative & 55 & 28 \\
\hline No Change & 90 & 46 \\
\hline Positive & 51 & 26 \\
\hline \multicolumn{2}{|c|}{ Degrees of Freedom = $2 \quad$ P-Value $=0.000$} \\
\hline \multicolumn{2}{|c|}{ Statistically significant P-value at the .05 level } \\
\hline
\end{tabular}

Table 4.34

Goodness-of-Fit Test for the Value Sense of Belonging

\begin{tabular}{|l|c|c|}
\hline Change in Value & $\begin{array}{c}\text { Frequency } \\
(n=196)\end{array}$ & $\begin{array}{c}\text { Percentage } \\
(100 \%)\end{array}$ \\
\hline Negative & 5 & 3 \\
\hline No Change & 165 & 84 \\
\hline Positive & 26 & 13 \\
\hline \multicolumn{2}{|c|}{ Degrees of Freedom =2 P-Value $=0.000$} \\
\hline \multicolumn{2}{|c|}{ Statistically significant P-value at the .05 level } \\
\hline
\end{tabular}

Table 4.35

Goodness-of-Fit Test for the Value Transference

\begin{tabular}{|l|c|c|}
\hline Change in Value & \multicolumn{1}{|c|}{$\begin{array}{c}\text { Frequency } \\
(n=196)\end{array}$} & $\begin{array}{c}\text { Percentage } \\
(100 \%)\end{array}$ \\
\hline Negative & 46 & 23 \\
\hline No Change & 64 & 33 \\
\hline Positive & 86 & 44 \\
\hline \multicolumn{2}{|c|}{ Degrees of Freedom = 2 P-Value $=0.000$} \\
\hline \multicolumn{2}{|c|}{ Statistically significant P-value at the .05 level } \\
\hline
\end{tabular}


Table 4.36

Goodness-of-Fit Test for the Value Warm Relationships with Others

\begin{tabular}{|l|c|c|}
\hline Change in Value & $\begin{array}{c}\text { Frequency } \\
(n=196)\end{array}$ & $\begin{array}{c}\text { Percentage } \\
(100 \%)\end{array}$ \\
\hline Negative & 25 & 13 \\
\hline No Change & 97 & 49 \\
\hline Positive & 74 & 38 \\
\hline \multicolumn{2}{|c|}{ Degrees of Freedom =2 P-Value $=0.000$} \\
\hline \multicolumn{2}{|c|}{ Statistically significant P-value at the .05 level } \\
\hline
\end{tabular}

\section{Summary}

The initial data collection took place in the summer of 2006 consisting of OB and NOLS participants. The two year follow-up data collection took place in 2008 with participants from the initial data collection. The ethnicity of participants for both data collections was overwhelmingly white or Caucasian and the majority of participants were adolescents and young adults either in high school or college. The majority of participants in both programs had never experienced a program with OB or NOLS before.

Using means-end analysis, Hierarchical Value Maps (HVMs) were run for all participants; and then for OB participants and NOLS participants separately. For all participants the attributes most frequently mentioned included group, expeditioning, overall course, wilderness, climbing, and instruction. The most frequently mentioned consequences included interactions, being challenged, personal growth, fun/excitement, new experience, and new perspective. The most frequently mentioned values included transference, selfrespect/esteem/confidence, sense of accomplishment, and warm relationships with others.

The HVM for all participants showed the majority of attributes associated with the consequence of being challenged. Being challenged then had a strong association with the 
consequence of interactions, which had a solid association with the consequence of leadership. All of the associations between the consequences eventually lead to the consequence of personal growth, which had a strong association with the value of sense of accomplishment. Sense of accomplishment had a strong association with the value of transference, which in turn had associations with the values of self-fulfillment, warm relationships with others, sense of belonging, self-awareness, self-respect/esteem/confidence, and fun and enjoyment of life. A comparison between the two data collections was done to investigate reported change in values over time. The statistical procedure of Pearson's chi-square test of independence was used to cross tabulate the program type with each change in a particular value. The tests revealed statistically significant results for the values of fun and enjoyment of life and transference and the conclusion was drawn that a relationship did exist between program type and change in these values over time. A chi-square goodness-of-fit test was also run for all eight values to test how the data was distributed across the categories of change. The results revealed statistical significance for all of the values and the conclusion was drawn that sample participants were not equally likely to report a negative, positive, and no change in the values tested. The next chapter will present a discussion and interpretation of the results, along with conclusions and future recommendations. 


\section{CHAPTER 5}

\section{DISCUSSION AND INTERPRETATION}

The purpose of this study was to gain a better understanding of the outcomes individuals experienced from participation in wilderness adventure programs and the effects they had on participants two years later. Summative reviews of the background and key literature are presented, along with reviews of the methodology and results. Interpretation and evaluation of the results are presented, along with relation of the results to previous literature and the limitations of the study. Conclusions will be drawn from interpretations of the results, with managerial and research implications as well as suggestions for future research.

\section{Summary}

\section{Review of Background of the Study and Key Literature}

A body of research has been conducted on the outcomes of wilderness adventure programs, especially on those offered by Outward Bound and NOLS. Hattie et al. (1997) looked at 96 unique studies related to the benefits of Outward Bound programs and concluded that these programs had positive effects on participants' interpersonal skills, leadership skills, sense of empowerment, self-control, independence, assertiveness, decision making skills, and self-esteem. Hattie et al. and Ewert \& McAvoy (2000) examined issues related to group dynamics in adventure programs and found that the programs had positive effects on both group dynamics and development.

Though the outcomes of wilderness adventure programs have been well documented, a few studies found that additional research was needed to deepen the understanding concerning how and why program elements contributed towards specific program outcomes (Ewert \& 
McAvoy, 2000; Hattie et al., 1997; McKenzie, 2000; McKenzie, 2003). According to Priest (1999b), "a descriptive base has been established as to what programs are like, what they contain, and what happens during them. However, very little research has been conducted on the relationships and influences that affect program outcomes" (p. 314). The wilderness adventure education research uncovered what has been referred to as a "black box", where it was widely accepted that adventure education worked, but researchers could not prove why or how (Ewert, 1983; McKenzie, 2000, Sibthorp et al., 2007). Sibthorp et al. found that the consequence of this black box was that, "many adventure programs continued to rely on anecdotal evidence and the assumption that simple participation led to participant development without the ability to articulate how change may occur (p. 1).

Researchers in the adventure education field have also called for more long-term study to track the outcomes of wilderness adventure programs on participants over time (Ewert \& McAvoy, 2000; Sibthorp, 2003; Sibthorp et al., 2008). Previous research has documented the immediate outcomes but few have documented the long-term outcomes associated with these programs (Goldenberg et al., 2005; Sibthorp et al., 2008). Tracking participant responses over time will allow researchers to measure whether participants are transferring the knowledge, skills, and values obtained from their program and applying these outcomes to their lives.

This study builds on previous research on wilderness adventure education that implemented means-end theory. This includes examinations of the factors associated with participation in a ropes course program (Goldenberg et al., 2000; Haras, 2003); the outcomes and related meanings associated with completing an Outward Bound program (Goldenberg et al., 2005); and the outcomes associated with participation in an integrated wilderness adventure program (McAvoy et al., 2006). While these studies helped establish a solid foundation for the 
use of means-end theory to further understand the behaviors and motivations of wilderness adventure education participants, they did not examine the transference of long-term personal outcomes.

In 2006, Dr. Marni Goldenberg embarked on a research study to examine the immediate and long-term outcomes experienced from participation in adventure education programs offered by Outward Bound and NOLS. This thesis is part of that longitudinal study.

\section{Review of Methodology}

This study employed means-end theory to examine the attributes, consequences, and values associated with participation in a wilderness adventure program. The initial data collection took place in the summer of 2006 when researchers interviewed participants of OB and NOLS programs. Follow-up phone interviews were conducted with the initial sample participants in 2008 .

The sampling frame for the initial data collection was limited to participants of Outward Bound courses in the Rocky Mountains of Colorado and NOLS courses in the Wind River Mountains of Wyoming. Courses sampled were limited to those that were seven days or longer. Subjects and courses were selected using a convenience sampling method. Semi-structured interviews were conducted with participants on a voluntary basis during the last two days of their course. The sampling frame for the two year follow-up data collection was limited to the initial study participants that were contacted and willingly agreed to follow-up phone interviews.

For the initial data collection, the researcher's hand-recorded participant responses on a pre-printed interview script (see appendix A). The first section of the script identified participant descriptive statistics; the next section asked for information about the subject's experiences on 
course, including duration of the course and activities participated in on course. In the last section of the interview subjects were asked to identify three to four of their favorite course components. Once subjects assembled their list of components, they were asked a series of questions for each stated component using the laddering technique.

The follow-up data collection utilized a single interview script similar to the one used in the initial data collection (see appendix B). The first section asked participants to remember three or four of the most meaningful components from their course. Once the participants assembled their short list of meaningful components or experiences, they were asked a series of questions using the laddering technique for each stated component. The last section of the script identified current participant descriptive statistics.

The laddering technique involved asking a series of open-ended questions that asked the respondent to identify the attributes that were important to them that they received from participating in their wilderness course. The respondent was then asked why a particular attribute was important. The response given was then the focus of the next, "why is that important?" question. This process of asking, "Why is that important?" continued for each response given until the respondent could no longer provide a meaningful answer. The procedure is called laddering because it represents a participant's thought progression from the attribute (course component) to its associated consequences and then on to higher values. This process of laddering responses was repeated for each of the components that the subject had identified in the interview.

Once interviews were collected, they were reviewed by the researchers, and content codes were developed based on participants' responses to the laddering process. Codes were created for three categories: attributes, consequences, and values. In the second step of data 
analysis the coded ladder categories were aggregated and used to develop an implication matrix, i.e., an asymmetric matrix that summarized the number of times each concept was associated with each of the other concepts in the respondents' ladders, determining the dominant connections between the key attributes, consequences, and values. The third step in data analysis was the development of hierarchical value maps (HVMs) which were based on the relationships identified in the implication matrix. The HVM provided a graphical summary that illustrated the relationships between the attributes, consequences, and values.

To help investigate the second objective of the study, to know whether participants were transferring the values from their experience back into their lives, a categorical statistical procedure was used. The statistical procedure of chi-square testing, specifically two types of hypothesis tests, a test of independence and a goodness-of-fit test where used. The test of independence tested whether a statistically significant difference existed between program type and the change in the number of times participants mentioned particular values from the initial data collection to the two year follow-up. The goodness-of-fit test investigated whether the change in the number of times participants mentioned particular values were distributed evenly across the three change categories or not.

\section{Summary of Results}

\section{Summary of Descriptive Findings}

In the original data collection the sampling frame consisted of 510 participants, 348 (68\%) from NOLS courses and $162(32 \%)$ from OB courses. Of the participants sampled 337 (66\%) were male and 173 (34\%) female. The overwhelming majority (88\%) of participants were white or Caucasian. Participants were grouped into age categories and the highest proportions 
were $16-17(41 \%), 14-15(20 \%)$, and 18-19 (17\%). The majority of participants (89\%) considered themselves students, either in high school or college. The majority of participants (91\%) had not previously attended a wilderness adventure course with NOLS or OB. The length of the courses for the majority of participants included 14-20 days (51\%) and 21-27 days (42\%). An overwhelming majority (99\%) of participants answered yes to whether they would recommend a course similar to their experience to friends.

In the two year follow-up data collection the sampling frame consisted of 197 participants, $108(55 \%)$ from NOLS courses and 89 (45\%) from OB courses. Of the participants sampled $128(65 \%)$ were male and $69(35 \%)$ female. The overwhelming majority (92\%) of participants were white or Caucasian. Participants were grouped into age categories and the highest proportions were 18-19 (40\%), 16-17 (27\%), and 20-21 (17\%). The majority of participants $(86 \%)$ considered themselves students, either in high school or college. The length of the courses sampled included 14-20 days (45\%) and 21-27 days (47\%). An overwhelming majority (98\%) of participants answered yes to whether they would recommend a course similar to their experience to friends.

Of the 162 OB participants in the original data collection $102(63 \%)$ were male and 60 (37\%) were female. Of the 89 OB participants in the two year follow-up data collection 52 $(58 \%)$ were male and $37(42 \%)$ were female. Of the 348 NOLS participants in the original data collection $235(67 \%)$ were male and 113 (33\%) were female. Of the 108 NOLS participants in the two year follow-up data collection $76(70 \%)$ were male and $32(30 \%)$ were female. 
Summary of Means-End Analysis

A means-end analysis was conducted with all of the individuals who participated in the two year follow-up data collection for this study ( $N=197)$. Hierarchical Value Maps (HVMs) were run for the entire sampling frame, as well as for OB participants and NOLS participants separately.

\section{All participants $H V M$}

The most frequently mentioned attributes included the following: group, expeditioning, overall course, wilderness, climbing, and instruction. The most frequently mentioned consequences included the following: interactions, being challenged, personal growth, fun/excitement, new experience, and new perspective. The most frequently mentioned values included the following: transference, self-respect/esteem/confidence, sense of accomplishment, and warm relationships with others.

The majority of attributes recalled by participants were associated with the consequence of being challenged. Being challenged had a strong association with interactions, which in turn led many participants to experience other consequences before leading to the consequence of personal growth. This sense of growth led the majority of participants to feel a sense of accomplishment, which then motivated them to transfer course benefits and outcomes to their lives. Transference led to warm relationships with others, which linked to sense of belonging and self-awareness. Self-awareness led many participants to more self-respect/esteem/confidence, which some participants associated with fun and enjoyment of life. 


\section{OB participants $H V M$}

A total of 89 participants were sampled from OB courses. The most frequently mentioned attributes included the following: group, expeditioning, solo, overall course, climbing, and wilderness. The most frequently mentioned consequences included the following: interactions, being challenged, new perspective, personal growth, new experience, and fun/excitement. The most frequently mentioned values included the following: transference, selfrespect/esteem/confidence, sense of accomplishment, warm relationships with others, and selfawareness.

The majority of the attributes in the OB HVM were associated with the consequence of being challenged. Being challenged did not have a direct connection to group interactions though the majority of $\mathrm{OB}$ participants mentioned interactions. Group interactions led participants to feel motivated and inspired, as well as exposed them to a new experience. All of the consequences eventually led to personal growth, which then linked to a sense of accomplishment. A sense of accomplishment led many participants to feel motivated to transfer course benefits and outcomes into their lives. Transference led to greater selfrespect/esteem/confidence for many participants. Some experienced more fun and enjoyment of life due to greater self-respect/esteem/confidence and a larger number experienced warm relationships with others. Warm relationships with others led to a sense of belonging and greater self-awareness.

\section{NOLS participants HVM}

A total of 108 participants were sampled from NOLS courses. The most frequently mentioned attributes included the following: group, expeditioning, overall course, wilderness, 
and instruction. The most frequently mentioned consequences included the following: interactions, personal growth, hard skill development, fun/excitement, being challenged, and environmental appreciation. The most frequently mentioned values included the following: transference, self-respect/esteem/confidence, sense of accomplishment, warm relationships with others, and fun and enjoyment of life.

The majority of the attributes in the NOLS HVM were associated with the consequence of interactions. The attributes of wilderness and climbing had strong associations with the consequence of new experience. The majority of NOLS participants mentioned interactions, which was a new experience for many participants. This new experience led to fun and excitement for many participants and fear and anxiety in a smaller population. Fun and excitement, as well as fear and anxiety caused about half of the NOLS participants to feel challenged. Eventually the consequences led to a sense of personal growth, which many NOLS participants associated with a sense of accomplishment. This sense of accomplishment then led to transference, which resulted in warm relationships with others, which then helped some participants to gain a greater sense of belonging and greater self-awareness. Greater selfawareness led the majority of participants to gain more self-respect/esteem/confidence, which helped some to experience more fun and enjoyment of life. A small number of participants experienced greater self-fulfillment as a result of more fun and enjoyment of life.

\section{Summary of Comparison of Data Sets}

A categorical statistical procedure was implemented to test whether a significant difference existed between program type, Outward Bound and NOLS, and the number of times the sample participants mentioned particular values over time, from the original data collection 
to the second year follow-up data collection. The statistical procedure of Pearson's chi-square test of independence was used to cross tabulate the program type with each change in a particular value. A test was run for all eight values. As a follow-up procedure a chi-square goodness-of-fit test was conducted for all eight values to test a hypothesis about how the data was distributed across the three categories of change.

Results of the chi-square tests of independence revealed statistically significant results for the values of fun and enjoyment of life and transference. These results allowed us to conclude that a relationship did exist between program type and change in the values of fun and enjoyment of life and transference. Tests of independence did not prove to be statistically significant for the others values, so a relationship could not be established between program type and change in these values.

Chi-square goodness-of-fit tests revealed statistically significant results for all of the values tested, allowing us to conclude that participants were not equally likely to report a negative, positive, and no change in all of the values. Transference and selfrespect/esteem/confidence were the only values where a higher percentage of participants showed a positive change over time. In all of the other values the highest percentage of participants revealed no change.

\section{Discussion}

\section{Descriptive Findings}

The descriptive statistics revealed that the majority of participants took their program with NOLS and were white males between the ages of 14-17, either in high school or college and had not previously attended a wilderness adventure education program. The overwhelming 
majority of participants stated they would recommend a course similar to the one they experienced to a friend, suggesting that the experience left a positive impression with them. In the two year follow-up the majority of participants consisted of white male NOLS participants who were between the ages of 16-21 and either in high school or college. The majority of participants stated they would still recommend a course similar to the one they experienced to a friend.

\section{Means-End Analysis}

\section{All Participants HVM}

The HVM for all participants revealed that the majority remembered being challenged by many of the attributes, including the group experience, expeditioning, and the overall course. Interactions with the group, defined as developing relationships, teamwork, and building community, was retained by the vast majority of participants as playing a major part in dealing with these challenges. A third of the participants sampled mentioned interactions with the group leading to learning about, displaying, or observing leadership. As a result of this exposure to leadership many participants learned and developed hard skills, such as cooking, tying knots, and belaying.

With the confidence developed from learning hard skills, many participants started to enjoy the experience, while others developed a new perspective, became motivated and/or inspired, and gained a sense of independence. This new perspective along with novel motivation/inspiration, lead many participants to feel a greater appreciation and awareness of the environment that surrounded them. The participants who began to enjoy the experience started to feel less stress as a result and began to focus on the environment surrounding them. 
Beginning to have fun and excitement on the course, along with greater awareness of the surrounding environment motivated some participants to reflect on the experience and on their life. This personal reflection, along with a sense of independence and a feeling of perseverance over challenges presented led many participants to acknowledge some personal growth or maturity. Many of the participants felt a sense of accomplishment as a result of this personal growth and this in turn motivated the majority of them to transfer the consequences and benefits from this experience to their lives. Transference occurred to a large degree in the value of warm relationships with others, which led some participants to feel a sense of belonging and to a greater extent, more self-awareness. This greater awareness of oneself led the majority of participants to gain more self-respect/esteem/confidence, which caused some participants to value fun and enjoyment of life.

\section{OB and NOLS HVMs: Similarities and Differences}

OB participants mentioned that the majority of the attributes from their courses led to being challenged. Though the majority of OB participants mentioned interactions with the group they did not make the direct association between that consequence and being challenged. NOLS participants on the other hand mentioned that the majority of the attributes from their courses led directly to interactions with the group, which some recalled as a new experience. These results suggest that the majority of NOLS participants associated the various attributes of their course with the group experience, while OB participants associated the attributes of their course as personal challenges.

Participants from both organizations did associate interactions with the group as a new experience, though NOLS participants mentioned this new experience leading to fun and 
excitement while $\mathrm{OB}$ participants mentioned it leading to fear and anxiety. These results suggest that the new experience of group interactions in the unique setting of the wilderness is leading to different consequences for the two programs studied. Further investigation into why this is the case could benefit future programming of the group experience for wilderness adventure programs.

Hard skill development was mentioned by half of the NOLS participants, stemming from leadership opportunities, a sense of independence, and perseverance through challenges presented. Only $13 \%$ of OB participants mentioned skill development, suggesting that development of hard, technical skills was either developed or emphasized more on the NOLS courses. Participants from both organizations mentioned personal growth leading to a sense of accomplishment which motivated them to transfer course outcomes back into their lives. Transference was mentioned by $78 \%$ of NOLS participants and $59 \%$ of OB participants, suggesting that transference of course consequences and benefits may be more prevalent in NOLS course participants.

For NOLS participants transference led to warm relationships with others, which led to a greater sense of belonging for some and greater self-awareness for others. This enhanced selfawareness led the majority of NOLS participants to greater self-respect/esteem/confidence and to a lesser extent more fun and enjoyment of life. For OB participants transference led to greater self-respect/esteem/confidence, which led to more fun and enjoyment of life and to a greater extent warm relationships with others. Warm relationships with others led some to greater selfawareness. These results suggest that $\mathrm{OB}$ participants focused on transference of course outcomes into intrapersonal values initially while NOLS participants initially focused on transference of outcomes into interpersonal values. 


\section{Comparison of Data Sets}

Results of the chi-square tests of independence revealed statistically significant results for the values of fun and enjoyment of life and transference. These results allowed us to conclude that a relationship did exist between program type and change in the values of fun and enjoyment of life and transference over time. Tests of independence did not prove to be statistically significant for the others values so a relationship could not be established between program type and change in these values.

Though the test of independence for the value of fun and enjoyment of life revealed that the NOLS participants mentioned this value more frequently than OB participants, in the majority of participants we saw no change over time. So the significant difference between the programs does not really say that much here since the majority of participants mentioned no change over time. But the test of independence revealed that a majority of NOLS participants showed a positive change in transference, while the highest percentage of OB participants showed no change. This suggests that the motivation to transfer course benefits and outcomes to other areas of participants' lives was greater for NOLS participants. This suggestion is supported by results from the HVMs where $78 \%$ of NOLS participants mentioned transference and only $59 \%$ of OB participants mentioned it.

Though the goodness-of-fit tests were statistically significant for all of the values, only transference and self-respect/esteem/confidence had a higher percentage of participants reveal a positive change over time. In all of the other values the highest percentage of participants revealed no change. These results suggest that the motivation to transfer course benefits and outcomes and greater self-respect/esteem/confidence where retained by the majority of participants over time. This suggestion is supported by results from the HVMs which showed 
that $71 \%$ of participants mentioned transference and $64 \%$ mentioned self respect/esteem/confidence.

\section{Relation of the Results to Previous Literature}

The results from the means-end analysis appear to have similarities with the practicaltheoretical based processing model that McKenzie (2003) adapted from the Outward Bound process model (see figure 2.2 from chapter 2). According to this model the participant is placed into unfamiliar wilderness and social environments, recalled by the majority of this study's participants. The participants are then given challenging course activities and problem-solving tasks, seen in this study in such attributes as overall course, expeditioning, climbing, camp craft issues, and small group expeditions. McKenzie also includes course instructors and their expectations, feedback, and characteristics as a vital component of the model. In this study instruction was one of the attributes mentioned by participants as well as the consequence of leadership, which included observing leadership from the instructors.

According to the model a state of adaptive dissonance is then created, seen in this study in such consequences as being challenged, fear/anxiety, fun/excitement, and new experience. This state leads to mastery, used to overcome dissonance and regain a state of equilibrium. Mastery is seen in this study through the consequences of hard skill development and gaining a new perspective. Mastery leads to reflection and reorganization of the meaning and direction of the experience, see in this study in such consequences as reflection, personal growth, independence, and sense of accomplishment. Reflection and reorganization then orients the participant toward living and learning for future experiences, seen in the study as transference, 
greater self-respect/esteem/confidence, greater self-awareness and self-fulfillment, more fun and enjoyment of life, a sense of belonging and warm relationships with others.

The similarities between the means-end analysis of this study and the McKenzie adaptation of the OB processing model should come as no surprise since many of the objectives of OB courses are based on this model and adaptations of this model. NOLS courses are based on similar processing models. Neill (2007b) stated that organizational philosophy and culture is one of the factors that influences the outcomes of adventure education programs and gives rise to program design, training of instructors, and communication with participants. OB and NOLS are not just taking participants out for a fun and exciting adventure and hoping that they get some benefits from the experience, on the contrary they are programming their courses to meet specific objectives and outcomes. The results from this study help to support this idea.

The results from this study suggest that transference of course consequences and benefits was occurring in participants' lives two years after their course had ended. These findings are consistent with other studies of transference of outcomes over time, including: overall impact (Hattie et al., 1997; Kellert, 1999), improved interpersonal skills and group development (Ewert \& McAvoy, 2000; Hattie et al., 1997; Sibthorp, 2003a; Sibthorp et al., 2008), and positive change in self-systems such as self-confidence/esteem/efficacy (Ewert \& McAvoy, 2000; Marsh et al., 1986; Paxton \& McAvoy, 2000; Propst \& Koessler, 1998; Sibthorp et al., 2008). Neill (2007b) concluded that transferability, including teaching skills that were directly applicable to everyday life and looking for metaphoric structures that related back to home life, was an important factor that influenced the outcomes that participants received from wilderness adventure education programs. 
Goldenberg et al. (2005) used the means-end approach to better understand the outcomes associated with completing an OB course. Some of the attributes, consequences, and values from Goldenberg et al. were coded similarly to the ones from this study, while others were coded differently. Though this was the case it was still deemed useful to compare the studies. Overall the differences between the means-end analyses of OB participant between the two studies seemed to reflect the timing in which the participants were interviewed. In Goldenberg et al. participants were interviewed immediately following their course, where the idea of transference was fresh in their minds as they prepared to head home. This transference led to greater selfconfidence/esteem and greater self-awareness and fulfillment. A sense of accomplishment was associated with greater self-confidence/esteem. The value of warm relationships with others was only mentioned by a small number of participants, who did not associate this value with transference or any of the other values.

The OB sample in this study came from participants that were being asked to recall their experience two years later. The first value they mentioned was a sense of accomplishment, which came after reflecting on an experience that led to growth and maturity. This sense of accomplishment then led the majority of participants to transfer the benefits gained from their course into various aspects of their lives, including greater self-systems (i.e., self-confidence, self-awareness) and warm relationships with others. It seems like the time to transfer course experiences and consequences, as well as time to reflect, allowed participants to search for deeper meaning from the values they received and to "connect the dots" between them.

Kellert (1999) is another longitudinal study that compared the outcomes from OB and NOLS programs. Kellert found differences in outcomes reflected varying program emphasis and philosophies, but concluded that more similarities than differences existed among the programs. 
Among the differences NOLS participants showed more pronounced changes in personal and character development and more interest in using the outdoor skills learned on course. These results were similar to this study were personal growth and skill development were consequences retained by a larger proportion of NOLS participants, as well as the values of transference and greater self-respect/esteem/confidence.

\section{Limitations of the Study}

A convenience sampling method was used to select OB and NOLS courses as well as to select participants; therefore the results cannot be generalized beyond the specific settings and population surveyed. A limitation of means-end theory and analysis is in the coding of participant responses when they get placed into general categories, in this case attributes, consequences, and values. Generalizing participant responses leaves room for misrepresenting meaning or ignoring it altogether for the sake of fitting a response into a category. For example, in the study there were a few negative outcomes reported by participants, but due to their small frequency, these responses were categorized under the larger, more neutral consequence of being challenged.

Another limitation of the study was the lack of consideration for other factors that could affect participant outcomes, such as program philosophy and culture. Though the argument was made in this study that program philosophy and culture had an affect on participant outcomes, the study was not designed to measure this. The study also did not measure or consider participant history, including factors influencing participants that occurred after their adventure program had ended. 
In the two year follow-up data collection only 197 of the original 510 participants were interviewed. This low attrition rate was due to the difficulty in contacting participants and getting them to complete interviews. The graduate student conducting the interviews implemented a system where three attempts to reach participants were made, if a participant could not be reached after three attempts then the graduate student would move on and attempt to contact other participants. Reasons that participants were not contacted included new and unknown contact information, messages informing them about the interview went unanswered, and phone calls were returned when the graduate student was not in the office.

Recall that a ladder in the means-end analysis is the association between an attribute, consequences, and value. The number of ladders that each participant completed varied from one to seven ladders. This study did not take into account the number of prompts or questions it took to get the participant to the next "ladder" in the interview process. The number of prompts or questions asked by the interviewer could have an affect on the overall frequency of attributes, consequences, and values mentioned. This would also affect the comparison of frequency of the outcomes mentioned between the two data sets.

\section{Conclusions}

The first objective of the study was to better understand the outcomes from participation in wilderness adventure programs. The research question posed out of this objective was to determine what the attributes, consequences, and values were for participants two years after participation in their course. A proportion of participants from the original study were interviewed and the means-end analysis did reveal the attributes, consequences, and values that these participants retained. The means-end analysis also revealed the associations between the 
attributes, consequences, and values. By investigating the associations between the attributes, consequences, and values inferences were made concerning how the outcomes came about.

From the means-end analysis we can infer that overall participants felt challenged by many of the attributes of their course. Interactions with the group helped participants to deal with the challenges presented. The confidence that came from the development of hard skills allowed participants to relax and have fun, develop new perspectives, become motivated and inspired, and develop a sense of independence. From the experiences and consequences of the course many participants developed a sense of growth and maturity, which led to a sense of accomplishment. This sense of accomplishment led the majority of participants to feel motivated to transfer course consequences and experiences back into their lives, revealed to a greater extent in warm relationships w/ others, greater self-awareness, and greater selfrespect/esteem/confidence.

The second objective of the study was to investigate the transference of values that participants' gained from their adventure experience. The research question posed from this objective was to find out if the values stated by participants immediately following their adventure experience had changed two years later. The results from the chi-square statistical analysis revealed that a positive change in participants' recollection of values had occurred in transference and self-respect/esteem/confidence, but no change had occurred in the other six values. This suggests that participants had transferred course consequences into their lives and experienced greater self-respect/esteem/confidence as a result. This suggestion is supported by results from the means-end analysis which revealed that $71 \%$ of participants mentioned transference and $64 \%$ mentioned self-respect/esteem/confidence, the two most frequently mentioned values. 
The chi-square tests also revealed that transference was recalled by a greater number of NOLS participants. These results suggest that transference of course consequences had occurred to a greater degree in NOLS participants. This suggestion is supported by results from the means-end analysis which revealed that $78 \%$ of NOLS participants mentioned transference compared to only $59 \%$ of OB participants.

\section{Recommendations}

\section{Managerial Implications}

Knowledge and understanding of the outcomes from participation in wilderness adventure courses can be useful to the administrative and managerial staffs of OB and NOLS as well as for decision makers with other wilderness adventure programs. The results of this study can be used for program development, including the training of course instructors and program evaluation. The findings can help with the creation of marketing and promotional materials, as well as aid programs that are attempting to obtain outside funding.

The more managers know about the outcomes from participation in their courses or those similar to their own and the associations between these outcomes the more knowledge they can apply to the planning of future courses. If a manager wants to design a program so that participants will have the opportunity to obtain specific values, it would be useful for them to understand the course components or attributes, as well as the consequences of these components that can lead to specific values. For example, results from this study show that transference of course outcomes into participants' lives was mentioned by the majority of the participants sampled. A manager aware of these results now has the incentive to design future programs to include activities and group discussions focusing on transference of course outcomes. 
This study has promotional implications for organizations that offer wilderness adventure programs. These organizations can promote the benefits and values that were found to be a result of participation in their courses as a way to entice new clients. By promoting particular benefits and values, such as gaining self-confidence or developing warm relationships with others, these organizations make what they are selling more attractive to potential clients. These organizations can apply this logic to sell specific types of programs as well. For example, to promote a two week long backpacking course, it can be advertised that participants have the potential to develop skills, as seen in previous backpacking courses, which will serve them for a lifetime of wilderness backpacking enjoyment.

Managers of wilderness programs can also use results from this study to help them obtain funding through grants, donations, and other sources. When applying for funding, many sources look for research to support the mission and objectives of organizations. If an organization has the research to backup what they claim to be doing, then they are more likely to be rewarded. For example, the current mission of NOLS is "to be the leading source of wilderness skills and leadership that serve people and the environment" (NOLS Mission, 2009, II 1). The results of this study help to support this assertion through the large number of participants that not only mentioned the consequence of skill development but also linked it to the consequences of leadership and motivation/inspiration.

The results from this study can also help with the training of wilderness adventure program instructors. It is important for instructors to be aware of the potential outcomes that participants may receive from a program. This knowledge can help them facilitate course activities with potential outcomes in mind and to provide sound advice to participants that are looking to them for guidance. The knowledge of outcomes that past participants have 
experienced provides instructors with more information to use to facilitate experiences for future participants.

\section{Theoretical Implications}

Means-end theory has been useful in understanding the outcomes obtained from participation in a wilderness adventure education program. By investigating the outcomes this study contributes to the body of knowledge concerning wilderness education. This research also adds to the field of wilderness education by examining the long-term affects of outcomes on participants' lives.

This study contributes to the body of means-end research that has examined outdoor education, including an examination of the factors associated with participation in a ropes course program (Goldenberg et al., 2000); the outcomes and related meanings associated with completing an Outward Bound program (Goldenberg et al., 2005); and the outcomes associated with participation in an integrated wilderness adventure program (McAvoy et al, 2006). This study contributes to this body of knowledge by examining the transference of personal outcomes from participation in wilderness adventure education programs into participants' lives.

\section{Suggestions for Future Research}

One limitation of this study was due to the convenience sampling method used, which limited the results to only those courses and participants sampled. Future research might want to use a random sampling method in order to apply the results to a broader population. The majority of participants of this study were Caucasian students between the ages of 14-19 years old. 
This thesis was part of a longitudinal study over a five year period. A large amount of data was collected. Future research using this study could investigate the differences and similarities between outcomes over time based on gender. Future research might also consider factoring in the number of prompts or questions participants were asked in the laddering process, which likely has an affect on participant responses and therefore an effect on frequency of outcomes. This would also need to be considered when comparing outcomes from multiple data collections over time. Future research could also compare the total frequency of each value over time, rather than compare the number of times each participant mentioned particular values, as done in this study. A simple comparison of frequency could be a more effective method to investigate whether participants were transferring outcomes over time.

Future research could also examine the previous outdoor experience of participants. This study asked participants if they had previously experienced a wilderness adventure course with either OB or NOLS, but did not ask them about overall experience in the wilderness. This information could lead to a comparison between those who had previous experience and those who did not. This is a variable that may have an effect on participants' outcomes.

Another suggestion for future research would be to consider the influence of other factors that could affect participant outcomes that were not considered in this study, such as program philosophy and culture, which leads to program design, training of instructors, and communication with participants. An instrument that included questions concerning the course instructors and their facilitation techniques may be interesting to look at for future studies, as well as consideration paid to specific program philosophy, culture, and course design.

Means-end theory lays a solid foundation to understanding emerging themes and patterns among the data collected. The theory can lead to inferences based on the emergent themes and 
patterns, but not to conclusions based on specific questions or hypotheses. A suggestion for future research is to use the data and emergent themes from a means-end analysis as a basis for further study. Grounded theory comes to mind as a theoretical framework that can use the themes and patterns generated from a means-end analysis and identify important variables to investigate further. A hypothesis can be developed based on these variables and then an instrument can be created to test the hypothesis. Grounded theories differ from other traditions in that theories are grounded in data generated through the research act and not developed before or after data analysis (Tilbury \& Walford, 1996). Grounded theory can compliment other approaches, in this case means-end analysis, to build a more complete picture.

For example, means-end theory was used to examine the attributes, consequences, and values of 40 participants who used the Appalachian Trail (Hill, Goldenberg, \& Freidt, 2009). From this study a benefits of hiking scale was developed and data was collected through a questionnaire of 454 Appalachian Trail users. The success of this study was instrumental in the development of a third research project replicating the benefits of hiking scale for Pacific Crest Trail users.

\section{Utility of the Research}

The results from this study show that wilderness adventure education programs have much to offer individuals and groups. Documenting the consequences and values that past participants have obtained from these programs leaves a road map for others to follow if they so choose. This study shows that the outcomes from participation in OB and NOLS programs can transfer into participants' lives, in such values as warm relationships with others, greater selfconfidence, and fun and enjoyment of life. The results support the idea that a wilderness 
adventure education program can have a lasting impression on one's life. This notion of transference helps make wilderness adventure education courses appealing to individuals and groups.

Finally, the results help to legitimize programs offered by OB and NOLS in the eyes of not only the general public but also with professional educators, therapists, counselors, and academics. Collecting empirical evidence that supports and refutes the assertions made by these organizations about the positive and beneficial outcomes that can come from participation in their programs only strengthens the position of adventure education as a legitimate form of experiential education. 


\section{REFERENCES}

Association for Experiential Education (AEE) (2009). What is experiential ed? Retrieved May 4, 2009 from AEE Web site: www.aee.org.

Bachert, D. (1999). The National Outdoor Leadership School: 40,000 wilderness experiences and counting. In J.C. Miles \& S. Priest (Eds.), Adventure programming (pp. 85-91). State College, PA: Venture Publishing.

Bacon, S. (1990). The evolution of the Outward Bound process. In A. Easley, J. Passineau, \& B. Driver (Eds.), The use of wilderness for personal growth, therapy, and education (pp. 3851). USDA Forest Service, General Technical Report RM-193.

Bagozzi, R., \& Dabholkar, P. (2000). Discursive psychology: An alternative conceptual foundation to means-end chain theory. Psychology \& Marketing, 17(7), 535-586.

Bagozzi, R., \& Dabholkar, P. (1994). Consumer recycling goals and their effect on decision making to recycle: A means-end chain analysis. Psychology \& Marketing, 11(4), 313340.

Bandura, A. (1969). Principles of behavior modification. New York, NY: Rinehart and Winston.

Bearden, R., Netemeyer, R., \& Mobley, M. (1993). Handbook of marketing scales: Multi-item measures for marketing and consumer behavior research. Newbury Park, CA: Sage Publications.

Carver, R. (1996). Theory for practice: A framework for thinking about experiential education. The Journal of Experiential Education, 19(1), 8-13.

Davis-Berman, J., Berman, D., \& Capone, L. (1994). Therapeutic wilderness programs: A national survey. Journal of Experiential Education, 17(2), 49-53. 
Ells, E. (1986). History of organized camping: The first 100 years. Martinsville, IN:

American Camping Association.

Ennis, C. (1999). A theoretical framework: The central piece of a research plan. Journal of Teaching in Physical Education, 18, 129-140.

Ewert, A. (1983). Outdoor adventure and self-concept: A research analysis. Eugene, OR: Center of Leisure Studies, University of Oregon.

Ewert, A., \& Heywood, J. (1991). Group development in the natural environment: Expectations, outcomes, and techniques. Environment and Behavior, 23, 592-615.

Ewert, A., \& McAvoy, L. (2000). The effects of wilderness settings on organized groups: A state-of-knowledge paper. USDA Forest Service Proceedings, 15(3), 13-26.

Feather, N. (1975). Values in education and society. New York, NY: Free Press.

Fielding, K., \& Hogg, M. (1997). Social identity, self-categorization, and leadership: A field study of small interactive groups. Group-Dynamics, 1(1), 39-51.

Ford, P. (1981). Principles and practices of outdoor/environmental education. New York, NY: John Wiley \& Sons.

Frauman, E., \& Cunningham, P. (2001). Using means-end approach to understand the factors that influence greenway use. Journal of Park and Recreation Administration, 19(3), 93113.

Frumkin, H. (2001). Beyond toxicity: Human health and the natural environment. American Journal of Preventive Medicine, 20, 234-240.

Gager, R. (1977). As a learning process... It's more than just getting your hands dirty. Voyageur, 1. Boulder, CO: Association for Experiential Education. 
Gardner, H. (2003). Multiple intelligences after twenty years. Paper presented at the American educational research association, Chicago, Illinois, April 2003.

Gardner, H. (1983). Frames of mind: The theory of multiple intelligences. New York, NY: Basic Books.

Gass, M. (1999). Transfer of learning in adventure programming. In J.C. Miles \& S. Priest (Eds.), Adventure programming (pp. 227-233). State College, PA: Venture Publishing.

Gengler, C., \& Reynolds, T. (1995). Ladder Map [Computer Software]. Camden, NJ: MeansEnd Software.

Goldenberg, M. (2002). Understanding the outcomes of outdoor adventure experiences using means-end analysis. Unpublished doctoral dissertation. University of Minnesota.

Goldenberg, M., Klenosky, D., O’Leary, J., \& Templin, T. (2000). A meansend investigation of ropes course experiences. Journal of Leisure Research, 32(2), 208224.

Goldenberg, M., McAvoy, L., \& Klenosky, D. (2005). Outcomes from the components of an Outward Bound experience. Journal of Experiential Education, 28(2), 123-146.

Gutman, J. (1982). A means-end chain model based on consumer categorization processes. Journal of Marketing, 46, 60-72.

Haras, K. (2003). An exploration of meaningful involvement in ropes course programs. Digital Dissertations, 64(12), 4621.

Hattie, J., Marsh, H., Neill, J., \& Richards, G. (1997). Adventure education and Outward Bound: Out-of-class experiences that make a lasting difference. Review of Educational Research, 67(1), 43-87. 
Hill, E., Goldenberg, M., \& Freidt, B. (2009). Benefits of hiking: A means-end approach on the Appalachian Trail. Journal of Unconventional Parks, Tourism \& Recreation Research, 2(1), 19-27.

Hirsch, J. (1999). Developmental adventure programs. In J.C. Miles \& S. Priest (Eds.), Adventure programming (pp. 13-27). State College, PA: Venture Publishing.

Hunt, J. (1999). Philosophy of adventure education. In J.C. Miles and S. Priest (Eds.), Adventure programming (pp. 115-122). State College, PA: Venture Publishing.

James, T. (1980). Can the mountains speak for themselves? Scisco Conscientia, 3.

Kahle, L. (Ed.). (1983). Social values and social change: adaptation to life in America. New York, NY: Praeger.

Kellert, S. (1999). A national study of outdoor wilderness experience. In R. Wizansky \& S. Reed (Eds.), new study demonstrates outdoor experience may prove life changing to adolescents, help solve education woes, The Outdoor Network, IX (4), 1-27.

Klenosky, D. (2002). The "pull” of tourism destinations: A means-end investigation. Journal of Travel Research, 40, 385-395.

Klenosky, D., Frauman, E., Norman, W., \& Gengler, C. (1998). Nature-based tourists' use of interpretive services: A means-end investigation. The Journal of Tourism Studies, 9(2), 26-36.

Klenosky, D., Gengler, C., \& Mulvey, M. (1993). Understanding the factors influencing ski destination choice: A means-end analytic approach. Journal of Leisure Research, 25(4), 362-379.

Knapp, C. (1994). Progressivism never died—it just moved outside: What can experiential educators learn from the past? Journal of Experiential Education, 17(2), 8-12. 
Kolb, D. (1984). Experiential learning. Englewood Cliffs, NJ: Prentice-Hall.

Kraft, R. (1999). Experiential learning. In J.C. Miles \& S. Priest (Eds.), Adventure programming (pp. 181-186). State College, PA: Venture Publishing.

Marsh, H., Richards, G., \& Barnes, J. (1986). Multidimensional self-concepts: A long-term follow-up of the effect of participation in an Outward Bound Program. Personality and Social Psychology Bulletin, 12, 475-492.

Martin, B., Cashel, C., Wagstaff, M., \& Breunig, M. (2006). Outdoor Leadership: Theory and practice. Champaign, IL: Human Kinetics.

Maslow, A. (1954). Motivation and personality. New York, NY: Harper.

McAvoy, L., Holman, T., Goldenberg, M., \& Klenosky, D. (2006). Wilderness and persons with disabilities: transferring the benefits to everyday life. International Journal of Wilderness, 12(2), 23-35.

McIntosh, A., \& Thyne, M. (2005). Understanding tourist behavior using means-end theory. Annals of Tourism Research, 32(1), 259-262.

McKenzie, M. (2000). How are adventure education program outcomes achieved: A review of the literature. Australian Journal of Outdoor Education, 5(1), 19-28.

McKenzie, M. (2003). Beyond "the Outward Bound process": Rethinking student learning. The Journal of Experiential Education, 26(1), 8-23.

Miner, J. (1999). The creation of outward bound. In J.C. Miles \& S. Priest (Eds.), Adventure programming (p.55-63). State College, PA: Venture Publishing.

Mulvey, M., Olson, J., Celsi, R., \& Walker, B. (1994). Exploring the relationships between means-end knowledge and involvement. Advances in Consumer Research, 21, $1-7$. 
Neill, J. (2006). Experiential learning and experiential education. Retrieved May 2, 2009, from http://www.wilderdom.com/experiential/.

Neill, J. (2007a). Overview: Outdoor education theory. Retrieved May 6, 2009, from http://www.wilderdom.com/theory/Overview.html.

Neill, J. (2007b). Factors which influence the effects of outdoor education programs. Guide to outdoor education research and evaluation. Retrieved April 13, 2009, from http://www.wilderdom.com/research/researchfactors.html

Neill, J., Gray, T., Ellis-Smith, G., Bocarro, J., Sierra, R., \& Desai, K. (2004). A psychoevolutionary theory of outdoor education. $2^{\text {nd }}$ International outdoor education conference, Bendigo, Australia, July 6-9, 2004. Retrieved May 12, 2009, from http://www.wilderdom.com/psycho-evolutionary/.

NOLS Courses. (2009). NOLS U.S. and international course offerings. Retrieved July 14, 2009 from http://www.nols.edu/courses/.

NOLS Mission. (2009). About Us: Mission and values. Retrieved May 10, 2009 from http://www.nols.edu/about/values.shtml.

Northern Illinois University. (2009). Lorado Taft field campus home page. Retrieved September 14, 2009 from http://www.niu.edu/taft/aboutus/index.shtml.

Oakes, P., Haslam, S., Morrison, B., \& Grace, D. (1995). Becoming an in-group: Reexamining the impact of familiarity on perceptions of group homogeneity. Social Psychology Quarterly, 58, 52-61. 
Olson, J., \& Reynolds, T. (1983). Understanding consumers' cognitive structures: Implications for advertising strategy. In L. Percy \& A. Woodside (Eds.), Advertising and Consumer Psychology, 1, (pp. 77-90). Lexington, MA: Lexington Books.

Outward Bound Community. (2009). Outward Bound in your community home page. Retrieved July 14, 2009 from http://www.outwardbound.org/index.cfm /do/obyc.index.

Outward Bound ELS. (2009). Expeditionary Learning Schools Outward Bound home page. Retrieved September 14, 2009 from http://www.elschools.org/.

Outward Bound History. (2009). History of Outward Bound in the United States. Retrieved July 14, 2009 from http://www.outwardbound.org/index.cfm/do/ind.about_history.

Outward Bound Professional. (2009). Outward Bound Professional home page. Retrieved September 14, 2009 from http://www.outwardbound.org/index.cfm/do/cp.professional.

Outward Bound Wilderness. (2009). Outward Bound wilderness expeditions home page. Retrieved July 14, 2009 from http://www.outwardbound.org/index.cfm /do/exp.index.

Paxton, T., \& McAvoy, L. (2000). Social psychological benefits of a wilderness adventure program. In S. McCool, D. Cole, W. Borrie, \& J. O’Loughlin (comps.) Wilderness science in a time of change conference, 3, 202-206; May 23-27 1999; Missuola, MT.

Piaget, J. (1952). The origins of intelligence in children. New York, NY: Basic Books.

Pieters, R., Baumgartner, H., \& Allen, D. (1995). A means-end chain approach to consumer goal structures. International Journal of Research in Marketing, 12, 227-244. 
Priest, S. (1999a). The semantics of adventure programming. In J.C. Miles \& S. Priest (Eds.), Adventure Programming (pp. 111-114). State College, PA: Venture Publishing.

Priest, S. (1999b). Research in adventure programming. In J.C. Miles \& S. Priest (Eds.), Adventure programming (pp. 309-317). State College, PA: Venture Publishing.

Priest, S. \& Gass, M. (1997). Effective leadership in adventure programming. Champaign, IL: Human Kinetics.

Propst, D., \& Koessler, R. (1998). Bandura goes outdoors: Role of self-efficacy in the outdoor leadership development process. Leisure Sciences, 20, 319-344.

Raiola, E., \& O’Keefe, M. (1999). Philosophy in practice: A history of adventure programming. In, J.C. Miles \& S. Priest (Eds.). Adventure programming (pp. 45-53). State College, PA: Venture Publishing.

Reynolds, T. \& Gutman, J. (1988). Laddering theory, method, analysis, and interpretation. Journal of Advertising Research, 28(1), 11-31.

Rokeach, M. (1973). The nature of human values. New York, NY: Free Press.

Roth, M. (1994). Enhancing consumer involvement in health care: The dynamics of control, empowerment, and trust. Journal of Public Policy \& Marketing, 13(1), 115-132.

Sibthorp, J. (2003). Learning transferable skills through adventure education: The role of an authentic process. Journal of Adventure Education and Outdoor Learning, 3(2), 145-157.

Sibthorp, J., Paisley, K., \& Gookin, J. (2007). Exploring participant development through adventure-based programming: A model from the National Outdoor Leadership School. Leisure Sciences, 29, 1-18. 
Sibthorp, J., Paisley, K., \& Furman, N. (2008). Long-term impacts attributed to participation in wilderness education: preliminary findings from NOLS. Proceedings of the CEO conference, Bradford Woods, IN, January 13, 2008, 1-4.

Tilbury, D. \& Walford, R. (1996). Grounded Theory: defying the dominant paradigm in environmental education research. In M. Williams (Ed.), Understanding Geographical and Environmental Education: The Role of Research (pp. 51- 64). London: Cassell Education.

Ulrich, R. (1984). View through a window may influence recovery from surgery. Science, 224, April 27, 420-421.

Veroff, A., Douvan, E., \& Kulka, R. (1981). The inner American: a self-portrait from 1957 to 1976. New York, NY: Basic Books.

Walsh, V. \& Golins, G. (1976). The exploration of the Outward Bound process. Denver, CO: Colorado Outward Bound School.

Webb, D. (1999). Recreational outdoor adventure programs. In, J.C. Miles and S. Priest (Eds.). Adventure programming (pp. 3-8). State College, PA: Venture publishing.

Wilson, E. (1984). Biophilia. Cambridge, MA: Harvard University Press. 


\title{
APPENDICES
}

\section{Appendix A: Initial Data Collection Interview Script}

\author{
Insights of an Outward Bound/NOLS Participant \\ Interview Script
}

Name:

Participation Number:

1. Male or Female

Introduction: Good morning/afternoon/evening. I'm , interviewing you on behalf of Outward Bound/NOLS Wilderness and California Polytechnic State University, San Luis Obispo. I am interested in understanding what you got from participating in your Outward Bound/NOLS course, and what it meant to you personally. Would you be willing to participate in a 10-minute interview? Is this a good time to do the interview?

If you agree to participate and are 18 or older, I will need you to sign a consent form. If you agree to participate and are under 18 , I will need to verify that your parents signed the consent form they received in your pre-trip packet.

As you know the purpose of this interview is to find out what you got out of your Outward Bound/NOLS course. There are no right or wrong answers to these questions. I want you to feel comfortable talking with me and answering my questions. Please be assured that all of your responses will remain completely confidential. Also, when answering a question please refer only to your most recent Outward Bound/NOLS course rather than any other previous outdoor experiences you might have had. Any questions for me? OK, let's begin?

\section{SECTION 1 - General Questions}

2. What year were you born? 19

3. Which of the following best describes you? (please "X" one)

$\square$ White or Caucasian $\quad \square$ Black or African American $\square$ Asian or Pacific Islander $\square$ American Indian/Native American $\quad \square$ Hispanic or Latino

$\square$ Other:

4. What is your current occupation? (please "X" one) $\square$ Student $\square$ Other:

5. Have you attended previous Outward Bound/NOLS Courses? $\square$ Yes $\square$ No

6. How many days was your Outward Bound/NOLS course? days

7. Which of the following did you participate in during your Outward Bound/NOLS course? ("X" all that apply)
$\square$ Backpacking
$\square$ Canoeing $\quad \square$ Rock Climbing
$\square$ Ropes Course $\square$ Solo

$\square$ Service Project $\square$ Personal Challenge Event 
Other, please list additional activities:

8. Would you recommend an Outward Bound/NOLS course to a friend? (please " $\mathrm{X}$ " one)
$\square$ Yes $\quad \square$ No
a. If no, please explain:

9. I am interested in what you feel where your favorite components out of your Outward Bound/NOLS course. Please tell me some of the components that stand out in your mind. Any others? (TRY TO GET AT LEAST 3-4... BUT ALLOW FOR MORE)

List of Components:

Ranking:

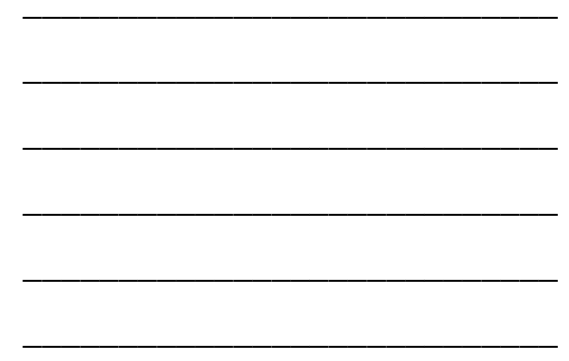

10. Now, I want you to think about the importance of each of these components. Which of the components you mentioned would you say is the most important to you? Which is the next most important? (REPEAT TILL ALL ARE RANKED)

\section{SECTION 2 - Laddering the Outcomes}

Now, I am going to ask you about some components that you mentioned. You should know that some of my questions will seem obvious or repetitive to you. It is not that I don't understand the obvious, it's just that I need to hear things in your own words to know exactly what you mean. Are you ready to begin?

COMPONENT \#1:

Now you mentioned that (component \#1) was something that you enjoyed about your Outward Bound/NOLS course. Why is important to you? important to you? ...And why is that

\section{COMPONENT \#2:}

Now you mentioned that (component \#2) was something that you enjoyed about your Outward Bound/NOLS course. Why is important to you? important to you? ...And why is that

\section{COMPONENT \#3:}

Now you mentioned that (component \#3) was something that you enjoyed about your Outward Bound/NOLS course. Why is important to you? important to you? ...And why is that 


\section{Appendix B: Two Year Follow-Up Phone Interview Script \\ Follow-up Interview Script}

Participant name:

ID\#:

Hi my name is ___ I'm calling with ___ regarding you interview two summers ago at the end of your outdoor course with researchers from Cal Poly, San Luis Obispo (remember we said we would be calling you back every so often). I'm hoping you can take a moment to share your current thoughts on your adventure experience.

If they need further convincing: The research we are gathering is about the long term effects of on people like you who participated. Your help in this research will help shape the future of targeting desired outcomes/benefits from past students.

Start interview:

I am interested in what you feel where the most meaningful experiences of your course. Please tell me a few of the components that still stand out in your mind. You don't need to explain why they stand out at this point, just what they are.

TRY AND GET AT LEAST 3-4 COMPONENTS FROM THEM. Remember that these are the attributes of their experience!

List of Components:

Component \#1 was , why was that important to you? Why did you remember that?

Why is (consequence mentioned above) important to you? What does it mean for you? 
Component \#2 was why was that important to you? Why did you remember it?

Why is (consequence mentioned above) important to you? What does it mean for you?

Component \#3 was why was that important to you? Why did you remember it?

Why is (consequence mentioned above) important to you? What does it mean for you?

Thank you for your openness about your experience. I just have a few more quick questions and then we are finished.

Gender:

Current age:

Ethnicity:

Current Occupation:

Current email:

Would you recommend NOLS/OB to people you know? YES NO 


\section{Appendix C: Combined Outcomes List - OB/NOLS DATA}

Attributes

Away from Home (AH)

Camp Craft (CC)

Climbing $(\mathrm{C})$

Expeditioning (E)

First Aid (FA)

Fishing (F)

Group (G)

Illness/Injury (II)

Independent Activities (IA)

Instruction (I)

Leadership Activities (LA)

Overall Course (OC)

Small Group Expeditions (SGE)

Solo (S)

Water Activities (WA)

Wilderness (W)

\author{
Consequence \\ Being Challenged (BC) \\ Environmental Appreciation (EA) \\ Fear/Anxiety (FeAn) \\ Fun/Excitement (FE) \\ Independence (Ind) \\ Interactions (Int) \\ Leadership (L) \\ Motivation/Inspiration (MI) \\ New Experience/Opportunity
}

(NEO)

New Perspective (NE)

Perseverance $(\mathrm{P})$

Personal Growth (PG)

Reflection (R)

Resourcefulness (Res)

Skill Development (SD)

Stress Relief/Relaxation (SRR)
Values

Fun \& Enjoyment of Life (FEL)

Self-Awareness (SA)

Self-Fulfillment (SF)

Self-Respect/Esteem/Confidence

(SREC)

Sense of Accomplishment (SoA)

Sense of Belonging (SoB)

Transference (T)

Warm Relationships w/ Others

(WRO)

Attributes: Characteristics or features of the experience

Away from Home

- Missing home

- Away from home for the first time

Camp Craft

- Preparing and cooking meals

- Camp chores

- Issues with tent

Climbing

- Rappelling

- Rock climbing

- Multi-pitch rock climbing

Expeditioning

- Hiking

- Backpacking

- Navigation

- River crossing

- Off-trail hiking

- Peak ascent

- Snow travel

First Aid

- WFR Certification and training Group

- Group experiences/Team activities

- People met/Friends made

- Fellow trip participants

- Volunteer and Environmental service
Illness/Injury

- Includes evacuations

Independent Activities

- Activities done alone

- Free time

- 20 mile run

- Differs from OB Solo Experience

Instruction

- Course instructors

- Skills learned

- Leave No Trace

Leadership Activities

- Leadership role

- Leader for the Day

Overall Course

- Overall experience or trip

- Course completion

Water Activities

- Rafting

- Swimming

- Kayaking

Wilderness

- Referring to natural environment

- Weather

- Getting away from urban/suburban environments 
Consequences: Benefits and/or perceived risks from course attributes

Being Challenged

- Personal physical/emotional challenges

- Group challenges

- Dealing with frustration

- Differs from perseverance

Environmental Appreciation

- Appreciation or awareness gained for natural environment

Fear/Anxiety

- Being scared or anxious during course

Fun/Excitement

- Feelings of joy or excitement

- Having fun

Independence

- Self-sufficiency

- Doing activities with instructors

- Doing things on one's own

Interaction

- Developing relationships

- Teamwork

- Building community

Leadership

- Learning about leadership

- Observing leadership

- Displaying leadership

Motivation/Inspiration

- Feeling motivated or inspired on course

New Experience/Opportunity

- "Physical" experience that was new

Values: Participants' desired end-states of being Fun and Enjoyment of Life

- Feelings of fun/enjoyment gained from course and applied to life

Self-Awareness

- Awareness of one's own individuality or personality

Self-Fulfillment

- Fulfillment of one's ambitions or desires through one's own efforts

Self-Respect/Esteem/Confidence

- Respect: Respect for oneself, character, conduct

- Esteem: Favorable impression of oneself

- Confidence: Confidence in one's own judgment, ability, power, etc.
New Perspective

- Developing a new perspective

Perseverance

- Preserving through a challenge or difficulty

- Differs from being challenged

Personal Growth

- Growing or maturing because of the course

- Character development

$\circ$ Becoming more outgoing

○ Being more patient

$\circ$ Feeling empowered

Reflection

- Personal reflection of one's growth or maturity during course

Resourcefulness

- Using what was available

- Being creative with available resources

Hard Skill Development

- Using skills learned or developed on course

○ Tying knots

○ Belaying

○ Cooking

Stress Relief/Relaxation

- Getting to relax

- Feelings of relief and relief from stress

- Feelings of comfort

Sense of Accomplishment

- Feeling good about completing course/task

Sense of Belonging

- Refers to sensing one's place in a group/culture/society/organization

Transference

- The motivation to transfer course benefits and consequences to another area of one's life (i.e., school, work, family)

- Future challenges

Warm Relationships w/ Others

- Refers to one's interactions with others

- Being better able to relate to others

- Feeling closer to other

- Altruism 
